\title{
13 Kathrin Rögglas Poetik des kreativen Dokumentarismus
}

Wäre man angehalten, nur einen einzigen Begriff zur Charakterisierung von Kathrin Rögglas Poetik auszuwählen, so würde man mit dem Begriff des ,Hybriden' keine schlechte Wahl treffen. ${ }^{899}$ Sämtliche künstlerischen Arbeiten Rögglas problematisieren vermeintlich klare Grenzziehungen, und zwar zwischen ganz unterschiedlichen Bereichen: zwischen Genres und Medien, Mündlichkeit und Schriftlichkeit, Fiktion und Realität, Ästhetik und Politik, Realismus und Fantastik. ${ }^{900}$ Der Nachdruck auf Phänomenen der Uneigentlichkeit, des Vermittelten und des ontologisch nicht eindeutig Klassifizierbaren deutet sich dabei bereits in vielen von Rögglas Werktiteln an: Man denke etwa an REALLY ground zero, FAKE reports, die alarmBEREITEN, die unVERMEIDlichen, besser WÄRE: keine, Die BEWEGLICHE Zukunft, von topüberzeugern und selbstUNGLÄUBIGEN oder die an der Universität Essen gehaltene Poetikvorlesung Von ZWISCHENmenschen, working Milieus, PARALLEL-Krisen und dem NICHT EINGELÖSTEN Futur (die einschlägigen Titelbegriffe sind jeweils groß gedruckt). Mit derartigen Markern der Vermitteltheit, Hybridität und Uneigentlichkeit weisen Rögglas Werktitel nicht so sehr darauf hin, dass man es hier mit defizitären Formen der jeweiligen Phänomene zu tun hätte; vielmehr machen sie deutlich, dass gewisse Phänomene überhaupt nur in vermittelter, hybrider oder uneigentlicher Form zu haben sind. Indem Röggla in ihren Texten Phänomene der Uneigentlichkeit in den Fokus rückt, betont sie die Abhängigkeit der Realität von - mit Michel Foucault zu reden ${ }^{901}$ - „Machteffekte[n]“ und

899 Die Ausführungen zu Kathrin Rögglas Dokumentarismus sowie zu wir schlafen nicht schließen an Überlegungen aus dem folgenden Aufsatz an: Navratil: Einspruch ohne Abbildung.

900 Röggla selbst bemerkt im Interview, dass „wechsel, ambivalenz, hybridität, spannung grundsätzliche ästhetische interessen von mir sind.“ (Kathrin Röggla / Olga Olivia Kasaty: Ein Gespräch mit Kathrin Röggla. In: Olga Olivia Kasaty: Entgrenzungen. Vierzehn Autorengespräche über Liebe, Leben und Literatur. München 2007, S. 257-287, hier S. 274).

901 Das Werk Michel Foucaults stellt einen bedeutenden philosophischen Bezugspunkt von Rögglas Schreiben dar. So hat Röggla wiederholt darauf hingewiesen, dass die Gouvernementalitätstheorie des späten Foucault einen wichtigen theoretischen Hintergrund für den Roman wir schlafen nicht bildet. Vgl. beispielsweise Kathrin Röggla: „Literatur ist ja nicht nur Theorie, sondern auch Erfahrung“. Ein Gespräch mit Kathrin Röggla. In: Kritische Ausgabe, Sommer 2007, S. 48-54, hier S. 48; Kathrin Röggla / Céline Kaiser / Alexander Böhnke: Die gouvernementalen Strukturen. Kathrin Röggla im Gespräch mit Céline Kaiser und Alexander Böhnke. In: Navigationen 4, 1/2 (2004), S. 171-184, hier S. 172. Allerdings hat sich Röggla von der Idee einer direkten Übertragung bestimmter Theorien in die Literatur distanziert: „[es ist] kein rei-

Ә Open Access. (C) 2022 Michael Navratil, publiziert von De Gruyter. (c) BY-NC-ND Dieses Werk ist lizenziert unter einer Creative Commons Namensnennung - Nicht-kommerziell - Keine Bearbeitung 4.0 International Lizenz. https://doi.org/10.1515/9783110763119-016 
„Wahrheitsdiskurse[n]“902, den Umstand also, dass die ,Wirklichkeit“ der Gegenwart in hohem Grade von narrativen, medialen und epistemischen Zurichtungen abhängig ist, sodass sich ein prädiskursiv-materieller Realitätswert mitunter gar nicht mehr angeben lässt.

Diese entschieden postmoderne Epistemologie scheint einer Betrachtung von Rögglas Werk unter dem Vorzeichen der Kontrafaktik zunächst im Wege zu stehen. Ginge man nämlich davon aus, dass Fakten und Fiktionen überhaupt nicht differenziert werden können, dann wäre zugleich auch der Kontrafaktik die Arbeitsgrundlage entzogen, beruht das Erzählphänomen doch gerade auf der Möglichkeit einer Unterscheidung von realweltlichen Fakten und deren Variation innerhalb einer fiktionalen Welt. Rögglas Poetik und Ästhetik würden allerdings missverstanden, wollte man darin einen nivellierenden Panfiktionalismus verwirklicht sehen. Mit Begriffen wie Diskurs, Fiktion, Fingiertes oder Fake, wie sie für die Poetik der Autorin zentral sind, wird bei Röggla nicht angedeutet, dass alles gleichermaßen Fiktion wäre, sodass die Literatur den Erfindungen der Realität lediglich eine weitere Erfindung hinzufügte. Vielmehr macht Röggla darauf aufmerksam, dass in der Realität selbst ein überaus komplexes Mischverhältnis zwischen Diskursivität und Materialität vorliegt, welches eine saubere Trennung zwischen beiden Bereichen massiv erschwert, mitunter sogar verunmöglicht. Die Unterscheidung zwischen Fiktion und Realität wird bei Röggla also nicht vollständig aufgegeben, sondern lediglich dahingehend verkompliziert, dass von einer Realität ausgegangen wird, die wesentlich durch Erfindungen, strategische Fiktionen und Diskurse mitkonstituiert ist, ohne dabei jedoch jemals ganz in Diskursen aufzugehen. Röggla schreibt:

Es gibt diese Welt da draußen, sie ist verdammt real und wir verdanken ihr sozusagen einige der angenehmsten und unangenehmsten Erfahrungen. Ich kann sie nicht so einfach wegknicken in Diskursen. Ich muss sie aufsuchen, mich auseinandersetzen. Das geht bei mir eben hin und her. ${ }^{903}$

Die Aufgabe der Literatur besteht für Röggla darin, sich mit dieser Hybridität der Realität ,auseinanderzusetzen', anstatt sie nur zu imitieren. Anhand eines Ein-

nes abbildverhältnis, weder eine eins-zu-eins-umsetzung der theorie foucaults noch neoliberaler verhältnisse, sondern, da es sich um ästhetik handelt, eine übersetzung, eine zuspitzung, eine strategie des umgangs, bzw. auf einer gestischen ebene geht es immer um widerstand.“ (Röggla / Kasaty: Ein Gespräch mit Kathrin Röggla, S. 269).

902 Michel Foucault: Was ist Kritik. Berlin 1992, S. 15. Röggla nimmt explizit Bezug auf diese Formulierung in Röggla / Kasaty: Ein Gespräch mit Kathrin Röggla, S. 261.

903 Kathrin Röggla: Die falsche Frage. Theater, Politik und die Kunst, das Fürchten nicht zu verlernen. Saarbrücker Poetikdozentur für Dramatik. Berlin 2015, S. 83. 
satzes genuin künstlerischer Mittel sollen die Verwerfungen der Realität selbst erfahrbar gemacht werden.

Im Folgenden soll gezeigt werden, dass und inwiefern sich die Kontrafaktik in Rögglas Werk als eine Möglichkeit der Auseinandersetzung mit der Hybridität der Realität begreifen lässt. Unter den in dieser Studie behandelten Autorenwerken stellt das Werk Kathrin Rögglas einer Analyse mit den Begrifflichkeiten der Kontrafaktik zweifellos die größten Schwierigkeiten in den Weg. Der klassische Fall einer kontrafaktischen Referenzstruktur - also eine einzelne Textproposition, die in offenkundigem Widerspruch zu einer konkreten Wahrheitsannahme über die reale Welt steht - findet sich in Rögglas Texten kaum. Auch hat Röggla selbst, anders als etwa Christian Kracht, den Begriff des Kontrafaktischen nie zur Charakterisierung der eigenen Poetik verwendet. Wenn im Folgenden Rögglas Werk nichtsdestoweniger unter dem Vorzeichen der Kontrafaktik interpretiert werden soll, so geschieht dies aus zwei Gründen: Erstens kann eine Applikation der eher kontraintuitiven Beschreibungskategorien der Kontrafaktik auf Rögglas Werk einige Charakteristika desselben hervortreten lassen, die sich nicht oder doch nur in geringerer Deutlichkeit greifen ließen, wenn man allein auf jenes Vokabular zurückgreifen würde, welches die Autorin selbst in ihren so sehr zahlreichen poetologischen Verlautbarungen bereitgestellt hat. ${ }^{904}$ Zweitens und dies ist systematisch von größerem Interesse - ermöglichst es ein Werk wie dasjenige Rögglas, den möglichen Extensionsbereich des Begriffs ,Kontrafaktik' genauer abzuzirkeln, indem man ihn bewusst bis zu seinen Rändern abschreitet, bis zu jenen Fällen also, die eine Beschreibung mit den Kategorien kontrafaktischen Erzählens nur noch eingeschränkt erlauben. Die Möglichkeiten, aber auch die Grenzen der Analysekategorie der Kontrafaktik können an einem Grenzfall wie dem Werk Rögglas mit größerer Deutlichkeit herausgearbeitet werden als an klassischen alternativgeschichtlichen, satirischen oder dystopischen Texten, bei denen ein Vorliegen kontrafaktischer Referenzstrukturen meist offenkundig, wenn nicht gar genrekonstitutiv ist.

904 Tatsächlich liegt bei Röggla geradezu eine auktoriale Überkommentierung des eigenen schriftstellerischen Schaffens vor: Röggla hat diverse Poetikdozenturen innegehabt, ist regelmäßiger Gast auf Podiumsdiskussionen zur politischen Gegenwartsliteratur, hat eine Vielzahl poetologischer Essays publiziert und sich in zahlreichen Interviews zu ihrer künstlerischen Arbeit geäußert. Derartige auktoriale Selbstdeutungen sind naturgemäß mit Vorsicht zu behandeln. Anders als im Falle Christian Krachts oder auch Leif Randts scheint mir allerdings wenig Anlass zu bestehen, den Äußerungen Rögglas über das eigene Werk grundsätzlich zu misstrauen. Entsprechend kann im vorliegenden Kapitel auch verschiedentlich auf Selbstaussagen Rögglas zur eigenen Poetik rekurriert werden. 
Einen Grenzfall der Kontrafaktik bilden Rögglas Texte in doppelter Hinsicht: Erstens findet eine Variation des Faktenmaterials, wie sie für die Kontrafaktik konstitutiv ist, bei Röggla vor allem in Hinblick auf die formale Gestaltung ihrer Texte und weniger in Bezug auf konkrete Inhalte statt. Entsprechend finden sich in ihren Texten auch kaum isolierte kontrafaktische Elemente. Bei Röggla treten nicht so sehr einzelne Textpropositionen in Widerspruch zu realweltlichen Faktenannahmen (obwohl auch dieser Fall vereinzelt vorkommt); stattdessen wird eine Variation von Faktenmaterial anhand sprachlich-formaler Verfremdungseffekte angezeigt. Anstelle einer inhaltlichen Kontrafaktik, wie sie sich in den Werken von Kracht, Zeh oder Randt nachweisen lässt, liegt in Rögglas Werk also eher eine Spielart formaler Kontrafaktik vor. ${ }^{905}$ Zweitens wird, wie oben erwähnt, in Rögglas Werk die Zuverlässigkeit und Gültigkeit der Fakten selbst als prekär ausgestellt, sodass sich Faktenwiedergabe und Faktenvariation mitunter nicht mehr zuverlässig voneinander unterscheiden lassen. Das heißt allerdings nicht, dass der Versuch, Fakt und Erfindung voneinander zu trennen, bei Röggla generell für hinfällig erklärt würde. Ganz im Gegenteil: Gerade mit Blick auf die politische Funktion von Rögglas Texten sind die Fragen, wie und wann spezifische gesellschaftliche Diskurse Fakten produzieren, aber eben auch, wie und wann diese Diskurse Fakten verzerren, verschleiern, oder strategisch umakzentuieren, von zentraler Bedeutung. ${ }^{906}$ Bei Röggla werden, wie zu zeigen sein wird, Verfahren wie die Kontrafaktik, welche prinzipiell auf klaren epistemischen Differenzierungen beruhen, gerade in ihrer postmodernen Verflüssigung genutzt, um auf den prekären Status der Fakten in der realen Welt zu verweisen.

Unter den vielfältigen Genres und Medien, in denen Röggla als Autorin produktiv ist, soll im Folgenden besonders auf jene Arbeiten eingegangen werden, die eine dokumentarische Dimension aufweisen (eindeutige Genrezuordnungen lassen

905 Siehe zu formalen Ausprägungen der Kontrafaktik Kapitel 4.3.4. Das Faktenverständnis der Kontrafaktik.

906 Eine Verbindung von Rögglas Poetik mit dem Problemfeld des ,Postfaktischen“ liegt nahe. In ihrer Bamberger Poetikvorlesung von 2017, die unter dem Titel Empathy with the Devil - Literatur in Zeiten der postfaktischen Behauptung stand, geht Röggla auf das Thema des Postfaktischen ein. Vgl. Kathrin Röggla: Die Bamberger Poetikvorlesung. In: Friedhelm Marx / Julia Schöll (Hg.): Literatur im Ausnahmezustand. Beiträge zum Werk Kathrin Rögglas. Würzburg 2019, S. 19-81, etwa S. 36f. Diese Vorlesung ist allerdings deutlich später entstanden als die in diesem Kapitel analysierten literarischen Texte. Um begriffliche und konzeptionelle Anachronismen zu vermeiden, wird im Folgenden auf die Verbindung von Rögglas Poetik mit dem Postfaktischen nicht weiter eingegangen. 
sich für Rögglas Texte kaum vornehmen ${ }^{907}$ ). Da der Dokumentarismus per definitionem mit realweltlichen Dokumenten, in gewissem Sinne also mit ,Fakten operiert, eignet sich das dokumentarische Schreiben in besonderer Weise, um die Rolle der Kontrafaktik im Werk Rögglas zu diskutieren. Rögglas dokumentarische Arbeiten werden im Folgenden als Manifestationsform eines kreativen Dokumentarismus gedeutet. Der Begriffsvorschlag ,kreativer Dokumentarismus' soll dabei solche dokumentarischen Verfahren fassen, die sich nicht auf die faktische Präsentation von Recherchematerial beschränken, sondern stattdessen die künstlerisch-schöpferische - eben kreative - Erfindung innerhalb des fiktionalen Textes besonders herausstellen. Die Spannung zwischen den Begriffsteilen ,kreativ' und ,Dokument' ist also durchaus intendiert. Wenn man mit Peter Weiss einen klassischen Dokumentarismus dadurch gekennzeichnet sehen kann, dass er „sich jeder Erfindung [enthält]“ und stattdessen „authentisches Material [...] im Inhalt unverändert [wiedergibt]“908, so zeichnet sich ein kreativer Dokumentarismus gerade dadurch aus, dass er die künstlerische Erfindung besonders betont. Anders als klassische Dokumentarismen ist ein solcher kreativer Dokumentarismus - wie eben beispielweise im Werk Rögglas - auch mit fantastischen oder kontrafaktischen Elementen vereinbar.

Zum ersten Mal hat Röggla im Jahre 2001 in ihrem 9/11-Text really ground zero auf dokumentarisches Material zurückgegeriffen. ${ }^{909}$ Seither konnte sich Röggla insbesondere mit ihren dokumentarischen Arbeiten als eine der bedeutendsten und individuellsten Stimmen der deutschsprachigen Gegenwartsliteratur etablieren. ${ }^{910}$ Das Verhältnis der Autorin zu Begriff und Verfahren des Dokumentarismus ist dabei ähnlich dynamisch wie ihr Verhältnis zu den meisten anderen ästhetischen Begriffen und Verfahren. Einerseits verwahrt sich Röggla gegen eine Einordnung ihrer dokumentarischen Arbeiten in die Tradition der klassischen Dokumentardramatik: „Ich schreibe [...] keine Dokudra-

907 Vgl. Iuditha Balint: Die Frage literarhistorischer Genrezuordnungen. Erika Runges Bottroper Protokolle (1968) und Kathrin Rögglas wir schlafen nicht (2004). In: Dies. / Tanja Nusser / Rolf Parr (Hg.): Kathrin Röggla. München 2017, S. 15-32.

908 Weiss: Notizen zum dokumentarischen Theater, S. $67 \mathrm{f}$.

909 Vgl. Kathrin Röggla: Im Moment durchkreuze ich den Feldbegriff mit meiner Arbeit. Kathrin Röggla im Gespräch mit Annett Gröschner. In: Annett Gröschner / Stephan Porombka (Hg.): Poetik des Faktischen. Vom erzählenden Sachbuch zur Doku-Fiktion. Werkstattgespräche. Essen 2009, S. 165-188, hier S. 167 f.

910 Die literaturwissenschaftliche Forschung hat sich denn auch vor allem mit Rögglas Texten ab really ground zero auseinandergesetzt. Einen hilfreichen Überblick zu Rögglas Frühwerk bietet Wiebke Eden: „Keine Angst vor großen Gefühlen“. Die neuen Schriftstellerinnen. Berlin 2001, S. 105-114. 
men. Was ich tue, hat mit Ästhetik zu tun. “911 In ihren Texten dokumentiert Röggla keine historischen Einzelereignisse, wie es etwa Heinar Kipphardt in seinem Dokumentardrama In der Sache J. Robert Oppenheimer getan hat; Rögglas Dokumentarismus behandelt vielmehr allgemeinere gesellschaftliche Tendenzen der Gegenwart. Gleichwohl autonomisiert sich Röggla in ihren dokumentarischen Arbeiten nicht vollständig vom Recherchematerial (was unter Wahrung des Begriffs ,Dokumentarismus‘ auch schwerlich möglich wäre). Die freie künstlerische Erfindung tritt in Rögglas Werk zurück zugunsten einer Bearbeitung vorgegebenen Diskurs- und Faktenmaterials. ${ }^{912}$

Den Begriff des ,Materials‘ hat Röggla selbst verschiedentlich in poetologischen Texten über ihre eigene künstlerische Arbeit gebraucht, dabei aber zugleich auf die Unmöglichkeit hingewiesen, das Material, welches sich bei der Recherche akkumuliert, in der Literatur auf quasi-objektive Weise wiederzugeben:

Der moralische Druck, dem Material gerecht zu werden, der in jeglicher Recherche sich erneut aufbaut, ist eine meiner ganz praktischen Hauptschwierigkeiten. Ich kann dem Material nämlich niemals gerecht werden. Bzw. mein Schreiben ist ja eine Reaktion darauf, die nicht darin besteht, scheinbare Objektivismen zu Tage zu fördern. ${ }^{913}$

Röggla betont hier einerseits die Schwierigkeiten, „dem Material gerecht zu werden“914; zugleich wird gerade die Unmöglichkeit, diesem Anspruch zu genügen, zu einer Quelle ihres Schreibens erklärt. Rögglas Dokumentarismus zielt mithin nicht darauf ab, das Material möglichst ,authentisch' wiederzugeben; vielmehr macht dieser Dokumentarismus darauf aufmerksam, dass der Versuch, qua Dokumentarismus zu einer etwaigen ,authentischen' Realität vorzudringen, meist nur „scheinbare Objektivismen zu Tage [fördert]“.

Blickt man auf die Themenwahl von Rögglas dokumentarischen Texten, so lässt sich ein gesteigertes Interesse an solchen Phänomenen erkennen, die

911 Kathrin Röggla / Barbara Petsch: Röggla: „Wir leben in restaurativen Zeiten“. Quelle: https://diepresse.com/home/kultur/news/608666/Roeggla_Wir-leben-in-restaurativen-Zeiten (Zugriff: 27.07.2021).

912 So bemerkt Röggla im Interview zu wir schlafen nicht: „Es gibt von dem, was da erzählt wird keine Fiktion in dem Sinne, dass ich mir Geschichten ausdenke. Ganz am Schluss des Buches geht es dann ein bisschen in einen Grenzbereich.“ (Röggla: „Literatur ist ja nicht nur Theorie, sondern auch Erfahrung“, S. 54).

913 Kathrin Röggla: Von Zwischenmenschen, working Milieus, Parallel-Krisen und dem nicht eingelösten Futur. Essenpoetik. Quelle: http://roeggla.net/wp-content/uploads/2015/12/ roeggla-essenpoetik.pdf (Zugriff: 27.07.2021), S. 42. Siehe etwa auch Kathrin Röggla: das stottern des realismus: fiktion und fingiertes, ironie und kritik. Paderborn 2011, S. 13.

914 An anderer Stelle bemerkt Röggla in analoger Weise, dass „literatur der so genannten wirklichkeit niemals gerecht werden kann, das ist auch nicht ihr auftrag“ (Röggla: das stottern des realismus, S. 6). 
auch ganz unabhängig von ihrer künstlerischen Bearbeitung in hohem Maße durch diskursive Zurichtungen bestimmt sind. Rögglas Dokumentarismus ist wesentlich Diskursdokumentarismus, ein Dokumentarismus also, der sich nicht so sehr auf die schlichte Faktizität der Realität bezieht, sondern vielmehr auf jene Diskurse und Narrative, welche die Realität selbst strukturieren. ${ }^{915}$ Das Material von Rögglas dokumentarischen Arbeiten zeichnet sich dabei stets durch eine ,effektive Virtualität‘ oder, um einen Begriff Ute Gröbels zu verwenden, ,synthetische Authentizität ${ }^{916}$ aus: Röggla wendet sich in fiktionalen Medien gesellschaftlichen Realitäten zu, die selbst bereits in hohem Maße durch Fiktion, Erfindung, Camouflage, wo nicht gar durch handfeste Lügen und fakes, in jedem Fall aber durch eine bestimmte diskursive Ordnung strukturiert und auf spezifische Wirkungen hin kalkuliert sind, in denen also „Sprechen eine performative Macht entfaltet““.917 Thematisiert werden etwa der Jargon der Unternehmensberatung in wir schlafen nicht, die Katastrophen-Berichterstattung in die alarmbereiten, das mediale und öffentliche Interesse am Fall Natascha Kampusch in Die Beteiligten oder die Arbeitsbedingungen von Simultandolmetschern in die unvermeidlichen. Bereits diese Themenwahl macht darauf aufmerksam, dass, in den Worten der Autorin, „die realität selbst etwas flüchtiges, irritierendes bekommen hat, sich mit fiktionen und fingiertem aufgeladen hat, und dass nur beschreibungsversuche etwas taugen, die ihre prekäre produktion mit hineinnehmen. “918 Mit ihren Texten versucht Röggla also nicht, die Realität von verstellenden Diskursen zu läutern. Vielmehr weist sie auf den „Konstruktionscharakter der Wirklichkeit“"919 selbst hin, beleuchtet also Diskurse als - um noch einmal eine Formulierung Foucaults

915 Auch Ursula Geitner hält fest: „Dokumentarisch heißt, jedenfalls bei Röggla, dass die Wirklichkeit nicht ,wiedergegeben', nicht schlicht abgefragt und auch nicht, wie es gern heißt, ,verdichtet" wird. Es steht nicht sie selbst (wie auch), sondern vielmehr stehen die über sie ergehenden Reden im Zentrum - und zur Disposition.“ (Ursula Geitner: Kathrin Röggla. Powerpoint-Folie zu ihrer Lesung am 31. Januar 2007 in Bonn. In: Kritische Ausgabe, Sommer 2007, S. 45-47, hier S. 46).

916 Ute Gröbel: 'short-sleeping, quick-eating and all that stuff' - Kathrin Röggla's Novel we never sleep and 'Deconstructive Documentarism'. In: Jörg von Brincken / Ute Gröbel / Irina Schulzki (Hg.): Fiktions/Realities. New Forms and Interactions. München 2011, S. 101-115, hier S. 105.

917 Kalina Kupczynska: Hinhören, weghören, aufhören. Mediale und diskursive Bewegungen in Die Alarmbereiten von Kathrin Röggla. In: Arnulf Knafl (Hg.): Reise und Raum. Ortsbestimmungen der österreichischen Literatur. Wien 2014, S. 160-172, hier S. 165.

918 Röggla: das stottern des realismus, S. 31.

919 Friedhelm Marx / Julia Schöll: Literarische Ausnahmezustände. Eine Einleitung. In: Dies. (Hg.): Literatur im Ausnahmezustand. Beiträge zum Werk Kathrin Rögglas. Würzburg 2019, S. 7-17, hier S. 8. 
aufzunehmen - „Praktiken [...], die systematisch die Gegenstände bilden, von denen sie sprechen. “920

Die beschriebene Themenwahl Rögglas ist dabei eng verknüpft mit der sprachlichen und anderweitigen formalen Gestaltung ihrer Werke. Rögglas Texte zeichnen sich durch eine Vielzahl von Verfremdungstechniken aus: $\mathrm{Zu}$ nennen sind etwa die konsequente Kleinschreibung, der Einsatz des Konjunktivs, komplexe Bild-Text-Relationen, Entpsychologisierung und Verwischung von Charaktergrenzen auf der Figurenebene, Genre- und Gattungshybridisierungen sowie Mehrfachbearbeitungen desselben Stoffes in unterschiedlichen Medien. ${ }^{921}$ Als künstlerische „waffen“, um „dieses unterscheidungsvermögen, um das es in der frage des politischen auf dem feld der literatur geht, zu verbessern“, nennt Röggla „die der montage, der zuspitzung, überzeichnung, übercodierung, der parodie, inversion, katachrese, rhythmischen verdichtung. “922 Derartige formale Irritationsmomente stellen keine autonomen ästhetischen Entscheidungen dar, sondern bilden vielmehr Reaktionen auf die ,effektive Virtualität' der dokumentierten Diskurse selbst: „Man kann“, so Röggla, „nicht einfach sagen, man hat seine Ästhetik, die gibt es schon vorher und die verwendet man und kippt dann irgendwelche Themen hinein, die dann irgendwie behandelt werden. So funktionieren literarische Texte nicht. “923 Anstatt also eine forciert avantgardistische Ästhetik an beliebiges Material heranzutragen, reagiert Röggla mit der spezifischen formalen Gestaltung ihrer Texte auf gesellschaftliche Phänomene, die bereits an und für sich über eine hochgradig irritierende, vermittelte oder gar unheimliche Dimension verfügen. Sie tut dies, indem sie einen künstlerischen Prozess zu initiieren sucht, der sich zwar strukturell an die realweltlichen Phänomene anlehnt, zugleich aber eine ästhetische Eigendynamik entfaltet. ${ }^{924}$ Programmatisch vertritt Röggla die Ansicht, „dass literatur immer eine zuspitzung, verschiebung, kommentierung liefert, mehr noch, dass das recherchierte in einem alchemistischen verfahren zur fiktion gerinnt, was

920 Michel Foucault: Archäologie des Wissens. Frankfurt a. M. 1973, S. 74.

921 Von wir schlafen nicht etwa existieren eine von der Autorin verantwortete Roman-, eine Bühnen- und eine Hörspielfassung.

922 Röggla: das stottern des realismus, S. $31 \mathrm{f}$.

923 Kathrin Röggla: „Literatur ist ja nicht nur Theorie, sondern auch Erfahrung“, S. 52.

924 So bemerken die Herausgeber des ersten Sammelbandes zu Rögglas Werk: „Rögglas poetische Verfahren sind [...] eng verbunden mit dem Inhalt ihrer Werke, sie arbeiten sich an den Phänomenen und Problemen der Gegenwart ab und machen sie zugleich auf einer werkästhetischen Ebene sichtbar.“ (Iuditha Balint / Tanja Nusser / Rolf Parr: Kathrin Rögglas Texte: Traditionslinien und Genres, literarische Verfahren, Diskurse und Themen. In: Dies. (Hg.): Kathrin Röggla. München 2017, S. 9-12, hier S. 11). 
weder mit der lüge, der unwahrheit oder dem realitätsverlust zu tun hat. “925 Gerade indem die Literatur die spezifischen Konstitutionsmechanismen der Realität selbst auf einer künstlerischen Ebene imitiert, kann sie zu einem besseren Verständnis dieser Realität beitragen. ${ }^{926}$ Diskursivität, Literarizität und die Eigenlogik der Fiktion kommen im Falle von Rögglas Arbeiten - anders als bei konventionelleren Formen dokumentarischen oder auch realistischen Schreibens - also nicht einfach als unvermeidliches, mediales Addendum zur beschriebenen Realität hinzu; vielmehr steht die diskursive Anlage von Rögglas Dokumentarismus in einem Resonanzverhältnis zu der sehr realen Vermischung von Realität und Fiktivität in der Gegenwart. ${ }^{927}$ Mit ihrer Betonung des Hybriden, Vermittelten und Uneigentlichen weisen Rögglas Texte darauf hin, dass „nicht nur der transfer der wirklichkeit in literatur eins zu eins eine schimäre ist, sondern die so genannte wirklichkeit selbst nicht eins zu eins zu haben ist“. ${ }^{928}$ Indem Röggla die Diskursivität der eigenen Texten mit der Diskursivität der beschriebenen Gegenwartsphänomene parallelführt, lässt sie den prekären Status dieser Phänomene anhand einer spezifisch künstlerischen Bearbeitung hervortreten.

Diesem „dialogische[n] prinzip“"929 vonästhetischer Form und realweltlichem Gegenstand kommt zentrale Bedeutung auch für die politische Dimension von Rögglas Schreiben zu. In ihrer Essener Poetikvorlesung bemerkt Röggla:

Der sogenannte Wahrheitsraum ist ein Aushandlungsraum, und an Aufklärung interessierte Schriftsteller müssen noch viel mehr als Journalisten sich mit der Gestaltung dieser Aushandlung auseinandersetzen. Es gibt also zahlreiche halbe Wahrheiten, die sich in diesem Raum aufhalten - was also davon werde ich vermitteln? Etwas Drittes, hoffe ich. Um das zu erreichen, also etwas jenseits von Agit Prop und dem Wunsch nach einer ideologisch korrekten Aussage, muss ich Abstand suchen, zu einem größeren Bild fin-

925 Röggla: das stottern des realismus, S. $6 \mathrm{f}$.

926 Röggla, so fasst Norbert Otto Eke die Überlegungen der Autorin zur eigenen Poetik zusammen, „spricht von Literatur als einem Erkenntnisinstrument, eine Funktion, die sie freilich nur dann erfüllen könne, wenn Literatur die sprachlich verfasste Wirklichkeit nicht mimetisch-realistisch widerzuspiegeln versuche, sondern diese vielmehr verdichte, übertreibe und so zur Kenntlichkeit entstelle.“ (Norbert Otto Eke: Vorwort. In: Kathrin Röggla: das stottern des realismus: fiktion und fingiertes, ironie und kritik. Paderborn 2011, S. 1-2, hier S. 2).

927 So konstatieren Friedhelm Marx und Julia Schöll: „Rögglas Texte thematisieren und sind Ausnahmezustände: Sie präsentieren Krisen, Wirklichkeitsrisse, Störfälle, Untergangsbilder und setzten diese zugleich performativ um. “(Marx / Schöll: Literarische Ausnahmezustände, S. 9).

928 Röggla: das stottern des realismus, S. 7.

929 Kathrin Röggla / Kristina Werndl: „Man bekommt spontan Lust zu pöbeln“. Quelle: http:// www.aurora-magazin.at/medien_kultur/werndl_roeggla_frm.htm (Zugriff: 27.07.2021). 
den, mit dem dieser Stoff korrespondiert. Korrespondiert er? Tritt er nicht vielmehr auf der Stelle? ${ }^{930}$

Röggla macht hier deutlich, dass politisches Schreiben, wie sie es versteht, wesentlich an eine bestimmte Konzeption der literarischen Form gebunden ist. Allerdings zielt Röggla dabei nicht darauf ab, die Realität selbst möglichst formadäquat in der fiktionalen Literatur wiederzugeben. Vielmehr versucht sie, etwas „Drittes“ zu schaffen, also eine formale Gestaltungsoption zu finden, welche die Realität weder einfach kopiert noch auch an die Stelle der Realität eine politische oder künstlerische Wunschvorstellung setzt. Entschieden distanziert sich Röggla von einem didaktischen Verständnis politischer Literatur, welches auf die Formulierung und Vermittlung klarer Botschaften hinausläuft:

zum realismus gehört die kritik, haben wir schon bei kluge gelesen, und er meinte damit nicht die verkürzung der kritik auf das moralische urteil oder das, worauf der text angeblich hinauswill. „worauf wollen sie hinaus?“ wird der autor ja auch andauernd gefragt. „was wollen sie uns eigentlich sagen?“ weiß er dann eine erschöpfende antwort auf diese frage, wird es mit dem ästhetischen projekt schwierig. denn nichts ist schlimmer als der belehrende autor, der seinen text auf eine botschaft hin ausrichtet. didaktik ist der feind der literatur. ${ }^{931}$

Anstatt politische Aussagen zu liefern oder konkrete Handlungsanweisungen zu geben - wie es in der Tradition der engagierten Literatur mitunter geschieht -, versucht Röggla, ihre künstlerischen Arbeiten durch eine spezifische formale Gestaltung politisch produktiv werden zu lassen. Wenn man hier überhaupt noch von politischem Engagement sprechen wollte, so nicht mehr im Sinne eines inhaltlichen Engagements der konkreten Botschaften, sondern allenfalls im Sinne eines, wie Ursula Geitner treffend formuliert, „formalen Engagements“. ${ }^{932}$ Ein solches Engagement lässt sich nicht mehr in einen inhaltlich eindeutigen Forderungskatalog übersetzen oder an politische Bewegungen mit einer klaren programmatischen Ausrichtung anschließen (eine

930 Röggla: Essenpoetik, S. 40.

931 Röggla: das stottern des realismus, S. 28. Auf die Frage, ob sie sich als politische Autorin bezeichnen würde, entgegnet Röggla im Interview: „mich interessieren gesellschaftliche knoten. mischverhältnisse. zusammenhänge. widersprüche. das sind politische fragestellungen, aber, wie gesagt, literatur kann nicht per se politisch oder nicht politisch sein, auch wenn sie in bestimmten historischen situationen politische reaktionen auslösen konnte. kunst scheint mir die aufgabe zu haben, wenn sie überhaupt aufgaben hat, ambivalenzen, widersprüche herauszuarbeiten.“ (Röggla / Werndl: „Man bekommt spontan Lust zu pöbeln“).

932 Geitner: Kathrin Röggla. Powerpoint-Folie zu ihrer Lesung am 31. Januar 2007 in Bonn, S. 47. 
Verbindung etwa von auktorialen politischen Interessen mit der politischen Agenda einer Partei, wie sie sich etwa bei Günter Grass' oder Juli Zehs zeitweiligem Einsatz für die SPD beobachten ließ, ist bei Kathrin Röggla schwerlich vorstellbar $^{933}$ ). Stattdessen muss die politische Stoßrichtung eines solchen formalen Engagements immer wieder aufs Neue anhand einer Analyse der künstlerischen Gemachtheit der Texte selbst herausgearbeitet werden.

Rögglas Werk wurde in der literaturwissenschaftlichen Forschung verschiedentlich als Manifestationsform eines ,neuen Realismus‘ angesehen, eines realistischen Schreibens also, welches einerseits ,authentisch bzw. dokumentarisch zu sein“ versucht, „dabei aber zugleich die Fiktionalitätstauglichkeit und den Konstruktionscharakter der jeweils thematisierten Praktiken, Themen und Diskurse hervorhebt. " 934 Für eine Diskussion von Rögglas Werk unter dem Vorzeichen der Kontrafaktik scheint diese Assoziation mit dem (neuen) Realismus zunächst ein Problem darzustellen, handelt es sich bei der Kontrafaktik doch um ein Verfahren, das sich hinsichtlich seiner Erzählgegenstände gerade vom Realismus - oder genauer: von Manifestationsformen der Realistik - absetzt. Blickt man jedoch etwas genauer auf Rögglas spezifisches Realismus-Verständnis, wie sie es in zahlreichen poetologischen Texten entwickelt hat und wie es sich in ihren künstlerischen Arbeiten umgesetzt findet, so löst sich diese vordergründige Schwierigkeit schnell auf. Rögglas Konzeption des Realismus erweist sich nämlich als durchaus kompatibel mit amimetischen Erzählverfahren wie der Kontrafaktik oder der Fantastik, ja umfasst derartige Erzählverfahren sogar als konstitutiven Bestandteil. Dezidiert setzt sich Röggla ab von „kümmerformen des realismus“, welche sich durch die naive Vorstellung auszeichnen, „plötzlich [würden] die autoren und autorinnen wieder losziehen in die welt und ihr qua recherche material entreißen, das sie dann nur ins rechte licht rücken müssten, und fertig ist der text. “935 Realismus im Sinne einer möglichst adäquaten Übertragung von Realität in Literatur oder ein „direktes weltabbildungsverhältnis“936 spielen also für Rögglas Realismus-Verständnis keine Rolle. Stattdessen bringt die Autorin Begriffe wie ,Aushandlung‘, ,Korrespondenz‘ und

933 Im Interview hat Röggla den Einsatz von Schriftstellerkollegen wie Günter Grass, Juli Zeh, Peter Rühmkorf oder Michael Kumpfmüller für die SPD als „ohnmachtsgeste“ bezeichnet. Vgl. Röggla / Werndl: „Man bekommt spontan Lust zu pöbeln“.

934 Balint / Nusser / Parr: Kathrin Rögglas Texte, S. 9. Siehe auch Tanja Nusser: „Realismus beginnt eigentlich immer, und das von allen Seiten, er ist eine permanente Aufforderung“. Über Kathrin Rögglas Texte. In: Søren R. Fauth / Rolf Parr (Hg.): Neue Realismen in der Gegenwartsliteratur. Paderborn 2016, S. 213-225.

935 Röggla: das stottern des realismus, S. 3, 5.

936 Röggla / Kasaty: Ein Gespräch mit Kathrin Röggla, S. 285. 
,Übersetzung‘ in die Diskussion ein. Gerade künstlerische Aushandlungs- und Formungsprozesse sieht Röggla als Mittel an, um in fiktionalen Texten diejenigen Dimensionen des Realen hervortreten zu lassen, welche in der Realität selbst mitunter verborgen bleiben: „Als realistisch kann nicht, wie Brecht bemerkte, die Abbildung einer Fabrik gelten, wir erfahren nichts darüber, was in ihr geschieht, sondern ein Übersetzungsverhältnis. Und da spielen Phantasie und Phantasmen eine große Rolle.“937 Die Begriffe ,Phantasie und Phantasmen' verweisen hier einerseits auf den Bearbeitungsprozess, den das Diskursmaterial in Rögglas künstlerischen Arbeiten durchläuft: Auch und gerade in Rögglas dokumentarischen Arbeiten wird das Recherchematerial in verfremdeter oder auch kontrafaktisch-variierter Form wiedergegeben, sodass eine naive Ineinssetzung von realweltlichem Material und fiktionalem Diskurs - also eine Rezeption im Modus der Faktik - ausgeschlossen ist. Darüber hinaus können die Begriffe ,Phantasie und Phantasmen“ mit Blick auf Rögglas künstlerische Produktion aber auch in einem mehr wörtlichen Sinne verstanden werden, nämlich als Hinweise auf die Transzendierung eines konventionellen Realismus-Verständnisses in Richtung der Fantastik.

Besonders augenfällig ist in diesem Zusammenhang Rögglas wiederholter Rekurs auf den Bereich des Gespenstischen, welcher bereits in mehreren ihrer Werktitel alludiert wird, etwa in totficken. totalgespenst. topfit, geisterstädte, geisterfilme, Die Lesbarkeit der Welt in gespenstischen Zeiten oder Gespensterarbeit und Weltmarktfiktion. Als Wesen zwischen An- und Abwesenheit erfüllen Gespenster in der Kunst häufig die Funktion von „Reflexionsfiguren der Medialität“. 938 Speziell in der Literatur der Moderne seit 1800 steht das Gespenst, wie Monika Schmitz-Emans festhält, „in einer Beziehung zu Vorstellungen über die Macht des Wortes und der Rede."939 Auch Röggla nutzt das Gespenstische, um den Hybridcharakter der von ihr beschriebenen Diskurs- und Medienphänomene hervorzuheben. ${ }^{940}$ Darüber hinaus setzt Röggla das Gespenstische aber

937 Röggla: Essenpoetik, S. 53.

938 Moritz Baßler / Bettina Gruber / Martina Wagner-Egelhaaf: Einleitung. In: Dies. (Hg.): Gespenster. Erscheinungen - Medien - Theorien. Würzburg 2005, S. 9-21, hier S. 11.

939 Monika Schmitz-Emans: Gespenstische Rede. In: Moritz Baßler / Bettina Gruber / Martina Wagner-Egelhaaf (Hg.): Gespenster. Erscheinungen - Medien - Theorien. Würzburg 2005, S. 229-251.

940 So hält Manuel Paß fest: „Die Struktur der gleichzeitigen An- und Abwesenheit teilt sich das Gespenstische mit zahlreichen programmatischen Themen Rögglas und wird so zu deren Reflexionsfigur.“ (Manuel Paß: Rögglas Gespenster. Das ,Gespenstische‘ als Reflexionsfigur in Kathrin Rögglas Normalverdiener. In: Friedhelm Marx / Julia Schöll (Hg.): Literatur im Ausnahmezustand. Beiträge zum Werk Kathrin Rögglas. Würzburg 2019, S. 123-140, hier S. 138). 
auch zur Erzeugung von Effekten des Unheimlichen ein (eine Kategorie, die in Rögglas Werk überhaupt eine zentrale Rolle spielt). ${ }^{941}$ Mitunter lassen sich in Rögglas Werk Phänomene des Gespenstischen sowie ganz generell Begriffe, Bilder und Sprechformen aus dem Assoziationsbereich der Fantastik nicht mehr in einem bloß metaphorischen Sinne interpretieren (und damit letztlich einer realistischen Lesart subsummieren); stattdessen persistieren sie durchaus in ihrem realitätsstörenden Potential. Rögglas fiktionale Welten verlieren damit stellenweise ihre Rezipierbarkeit in den Modi der Realistik oder Faktik, wie sie das dokumentarische Erzählen traditionellerweise auszeichnen, und gehen in den Bereich amimetischen Erzählens über.

Beide Aspekte, die Tendenz zur formalen Verfremdung einerseits und die Transzendenz des Realismus in Richtung Fantastik andererseits, spielen eine zentrale Rolle bei dem Versuch, Rögglas Dokumentarismus als Manifestationsform der Kontrafaktik zu deuten. Wofern sich die künstlerische Verfremdung nämlich nicht auf allgemeine Realitätsannahmen, sondern auf konkrete Fakten der realen Welt bezieht (und letzteres wird im Falle Rögglas ja bereits durch den Begriff ,Dokumentarismus“ suggeriert), kann sie, die Verfremdung, durchaus als formale Realisationsform der Kontrafaktik angesehen werden. Auch die Überlagerung von faktischen Einzelinformationen - eben dem dokumentarischen Faktenmaterial - mit fantastischen Eigenschaften legt eine Deutung im Weltvergleichsverhältnis der Kontrafaktik nahe, ja erfordert eine solche sogar, insofern die Rezeption eines realweltlich-konkreten Elements im Modus der Fantastik notwendigerweise zugleich eine Rezeption im Modus der Kontrafaktik impliziert. ${ }^{942}$

Eine Verbindung von Rögglas ,neuem Realismus‘ mit der Kontrafaktik erscheint nicht zuletzt deshalb naheliegend, weil sich die Autorin immer wieder intensiv mit Genres und Gattungen auseinandergesetzt hat, die eine entschiedene Neigung zum Einsatz von Fantastik oder Kontrafaktik aufweisen: etwa mit dem Katastrophenfilm, der Dystopie oder dem Märchen. ${ }^{943}$ So fordert Röggla in ihrem Essay die rückkehr der körperfresser „einen anderen katastrophenfilm“ -

941 Zum Unheimlichen in Rögglas Werk siehe etwa David Clarke: The Capitalist Uncanny in Kathrin Röggla’s wir schlafen nicht: Ghosts in the Machine. In: Angermion 4 (2011), S. 147-163; Julia Schöll: Dead or alive. Räume des Unheimlichen bei Kathrin Röggla. In: Friedhelm Marx / Julia Schöll (Hg.): Literatur im Ausnahmezustand. Beiträge zum Werk Kathrin Rögglas. Würzburg 2019, S. 107-121.

942 Siehe Kapitel 5.1. Realistik, Fantastik, Kontrafaktik, Faktik.

943 Siehe exemplarisch Kathrin Röggla: disaster awareness fair. zum katastrophischen in stadt, land und film. Wien 2006; dies.: Essenpoetik. 
und scheint dabei unter der Hand zugleich den eigenen Dokumentarismus zu charakterisieren, wenn sie schreibt:

solche filme müssten hybride mischungen sein, man dürfte nicht entscheiden können, ob sie dokumentarfilme oder fictionfilme sind, man dürfte sie überhaupt nicht zuordnen können, die erste reaktion auf diese filme müsste sein ,was ist denn daaas!?!` [...]

es müssten filme sein, die sich auf der höhe des zuschauers bewegen, also von einer welt erzählen, aus deren tatsächlichem zusammenhang unsere gegenwärtigen katastrophen entstehen, nicht die filme, die das futur gepachtet haben, sondern die, die uns fest gebucht haben. ${ }^{944}$

Einmal mehr zeigt sich hier die Bedeutung des Hybriden für Rögglas Poetik, wenn sie den Inhalt von Katastrophenfilmen gerade nicht - wie gemeinhin üblich - in eine ferne Zukunft oder in eine Parallelwelt verlegt, sondern darauf aufmerksam macht, dass auch die Gegenwart längst mit Krisendiskursen und dystopisch anmutenden Phänomenen durchwirkt ist. Scheinbar paradox nutzt Röggla konventionell als amimetisch konzeptualisierte Genres wie Katastrophenfilm und Dystopie, um zu einer neuen Form realistischen Schreibens zu gelangen: „Heute bin ich im problematischen Futur angekommen mit meiner Dystopie. Irgendwie scheine ich das Genre zu brauchen, um zu einem vernünftigen Realismus zu kommen.“945 Selbst dem Märchen, also einer genuin fantastischen Gattung, schreibt Röggla ein produktives Potenzial für die Generierung eines ,neuen Realismus“ zu: „die interessantesten realisten“, so bemerkt Röggla in Bezug auf die Schriftstellerkollegen Alexander Kluge und Tim Etchells, „halten es oft mit dem märchen“. ${ }^{946}$ Fantastisches, realitätsvariierendes oder eben kontrafaktisches Erzählen stehen für Röggla entsprechend in keinem Ausschlussverhältnis zu Realismus und Dokumentarismus. Im Gegenteil bieten gerade diese vordergründig amimetischen Erzählverfahren eine Möglichkeit, um sich auf künstlerischem Wege einer gesellschaftlichen Realität anzunähern, in der, wie Röggla schreibt, „das Fiktive das Reale überwuchert hat““.947

Rögglas Einsatz der Kontrafaktik soll im Folgenden vor allem anhand einer Interpretation des Romans wir schlafen nicht aus dem Jahre 2004 erläutert werden. Es handelt sich dabei um einen kreativ-dokumentarischen Text, der auf einer Reihe von Interviews beruht, die Röggla mit Vertretern der New Economy geführt hat. Dem Roman liegt also zweifellos realweltliches Faktenmaterial zugrunde. Allerdings wird dieses Material in massiv verfremdeter Form präsen-

944 Kathrin Röggla: die rückkehr der körperfresser. In: Dies.: disaster awareness fair. zum katastrophischen in stadt, land und film. Wien 2006, S. 31-51, hier S. $49 \mathrm{f}$.

945 Röggla: Essenpoetik, S. 53.

946 Röggla: das stottern des realismus, S. 9.

947 Kathrin Röggla: Gespensterarbeit und Weltmarktfiktion. In: Dies.: besser wäre: keine. Essays und Theater. Frankfurt a. M. 2013, S. 209-232, hier S. 209. 
tiert, sodass man es hier mit - teils inhaltlichen, vor allem aber formalen - kontrafaktischen Variationen zu tun hat. Der ausführlichen Interpretation von wir schlafen nicht folgt ein kürzerer Exkurs zu dem Text wilde jagd aus Rögglas Prosaband die alarmbereiten. Anders als in wir schlafen nicht beruht das alludierte Faktenmaterial bei diesem Text nicht auf individuellen Recherchen der Autorin, sondern ist der öffentlich-medialen Berichterstattung rund um die Entführung und Befreiung von Natascha Kampusch entnommen. Entsprechend kann dieses Material, im Gegensatz zu den Interviewmitschriften von wir schlafen nicht, als allgemein bekannt vorausgesetzt werden, was auch eine Veränderung in der kontrafaktischen Verweisstruktur nach sich zieht. Diese spezifische Variante der Kontrafaktik soll abschließend knapp beleuchtet werden, um auf diese Weise die formale Bandbreite von Rögglas kreativem Dokumentarismus in unterschiedlichen ihrer Werke anzudeuten.

\subsection{Kathrin Röggla: wir schlafen nicht}

Angesichts der hohen Bedeutung, der das Ikonische im Werk Kathrin Rögglas zukommt - für einige ihrer Buchprojekte hat Röggla intensiv mit dem Bildkünstler Oliver Grajewski zusammengearbeitet -, erscheint es naheliegend, der Buchgestaltung von Rögglas Publikationen erhöhte Aufmerksamkeit zu widmen.

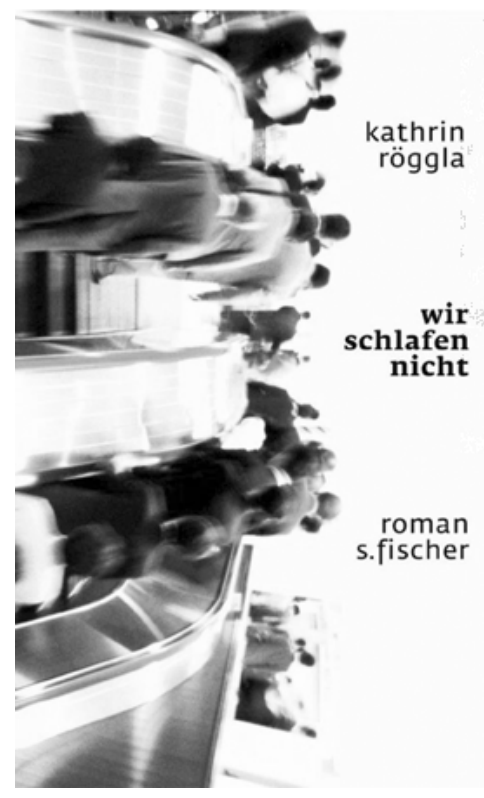

Abbildung 4: Cover von Kathrin Rögglas wir schlafen nicht. 
Auf dem Cover der Fischer-Ausgabe von wir schlafen nicht, reproduziert in Abbildung 4, ist die Fotografie einer Rolltreppe zu sehen, auf der - von hinten aufgenommen - vorwiegend männliche Personen in Business-Anzüge nach oben befördert werden. Die Bildachse ist dabei vertikal ausgerichtet, sodass die Figuren auf die Seite gekippt erscheinen. Darüber hinaus sind die Konturen der Figuren verwischt und die Farben unnatürlich intensiv: Die wenigen sichtbaren Hautpartien erscheinen beinahe rot. Diese Elemente sowie ihre Verfremdung weisen dabei sowohl inhaltlich als auch formal auf Rögglas Text voraus: Über die Gesichtslosigkeit und weitgehende Austauschbarkeit der abgebildeten Figuren wird hier einerseits thematisch die desubjektivierende Arbeitswelt der New Economy aufgerufen, welche das inhaltliche Zentrum von Rögglas Text bildet. Andererseits lässt sich die formale Verfremdung der Bilddarstellung auf die formalen Verfremdungsverfahren von Rögglas kreativem Dokumentarismus beziehen. Eine Referenz auf realweltliches Faktenmaterial in diesem Falle: die reale Rolltreppe und die darauf beförderten Menschen wird hier zweifellos etabliert (Fotografien implizieren ja bereits qua Medium eine konkrete Realitätsreferenz ${ }^{948}$ ). Zugleich aber wird diese Referenz formal verfremdet: Reale Menschen haben keine derart rote Hautfarbe und gehen auch nicht seitlich gekippt durch die Welt. ${ }^{949}$ Es liegt hier also gewissermaßen eine Form ,pikturaler Kontrafaktik' vor: eine Variation realweltlichen Faktenmaterials in bildlicher Form. Anders jedoch als bei den Coverabbildungen von Richard J. Evans Altered Pasts, die im Theorieteil der Arbeit diskutiert wurden ${ }^{950}$, handelt es sich hier nicht um eine Überschreibung einzelner historischer Informationen mit offenkundigen Fehlreferenzen. Stattdessen wird anhand verschiedener Verfremdungsverfahren auf eine Destabilisierung der dargestellten Welt als ganzer (oder aber eine verfremdete Darstellung dieser Welt) hingedeutet. ${ }^{951}$ Die

\footnotetext{
948 Vgl. Werle: Fiktion und Dokument, S. $117 \mathrm{f}$. Bezeichnenderweise wurden bei Rögglas nachfolgenden Buchpublikationen, die nicht auf realen Interviews beruhen, - also tokio, rückwärtstagebuch, die alarmbereiten und Nachtsendung. Unheimliche Geschichten - keine Fotografien mehr für das Cover verwendet.

949 Ebenfalls eine um 90 Grad gedrehte Fotografie wird auf der Coverabbildung von Thomas Brussigs Alternate History-Roman Das gibts in keinem Russenfilm verwendet.

950 Siehe Kapitel 4.3.4. Das Faktenverständnis der Kontrafaktik.

951 Die Unterscheidung von Welt- und Darstellungsebene bildet ein generelles Problem der Semiotik fiktionaler Bilder. So ist zum Beispiel im Comic nicht ohne Weiteres entscheidbar, ob Donald Duck innerhalb der fiktionalen Welt des Comics eine Ente ist, oder ob er innerhalb der fiktionalen Welt ein Mensch ist, der nur als Ente gezeichnet wurde. Siehe hierzu Stephan Packard: Anatomie des Comics. Psychosemiotische Medienanalyse. Göttingen 2006, S. 104.
} 
Faktenvariation betrifft hier also eher die Form als den Gegenstand des Bildes was freilich nicht bedeutet, dass diese formale Variation ohne Einfluss auf die Interpretation des Bildes bliebe. Auf kongeniale Weise deutet das Cover von wir schlafen nicht auf Verfahren einer formalen Kontrafaktik voraus, wie sie dann auch in Rögglas Text zum Einsatz kommen.

wir schlafen nicht thematisiert die Arbeitsbedingungen, Subjektivierungsprozesse und Ideologeme der New Economy, jenes Wirtschaftszweigs also, der von der klassischen Warenproduktion vor allem auf webbasierte Dienstleistungen umzusatteln versuchte und der seinen größten Aufschwung in den 1990er Jahren erlebte, ehe dann im Jahr 2000 mit dem Platzen der sogenannten ,Dotcom-Blase، die harte wirtschaftliche Ernüchterung folgte. wir schlafen nicht erschien 2004, die Textentstehung liegt also in den Jahren unmittelbar nach dem Boom der New Economy. ${ }^{952}$ Rögglas Text nimmt eine spezifische Teilbranche der New Economy in den Blick: die Berufsgruppe der Unternehmensberater.

Auf dem inneren Titelblatt wird wir schlafen nicht als „roman“ (wsn, 3) bezeichnet. ${ }^{953}$ Die typischen Gattungserwartungen jedoch unterläuft Rögglas Text auf vielfältige Weise: wir schlafen nicht weist weder eine zentrale Erzählinstanz noch eine klare Handlung auf. Handlungszeit und Handlungsort - ein Messegelände - müssen sukzessive im Laufe der Lektüre erschlossen werden. ${ }^{954}$ Rögglas Text vereint, wie Iuditha Balint bemerkt, „Charakteristika verschiedener Genres wie der Dokumentation, des Berichts, des Dramas, des journalistischen Interviews und des Romans." 955 Konkret setzt sich der Text zusammen aus einer Reihe von Sprecherpassagen, verteilt auf sieben Figuren mit Berufen wie „key account managerin“, „praktikantin“ oder „senior associate“ (wsn, 5). Das Sprachmaterial dieser Passagen geht dabei, wie bereits erwähnt, auf eine Reihe von Interviews zurück, die Röggla mit Vertretern der New Economy geführt hat. Diese Interviews werden im Text allerdings nicht unverändert wiedergegeben, sondern in komprimierter und rhythmisierter Form präsentiert, nach thematischen und dramaturgischen Gesichtspunkten geordnet sowie auf nur sieben Sprecher verteilt. wir schlafen nicht weist somit einerseits eine dokumentarische Dimension

952 Vgl. Balint: Die Frage literarhistorischer Genrezuordnungen, S. 15.

953 Zitate aus wir schlafen nicht werden nach folgender Ausgabe mit der Sigle „wsn“ im Text gegeben: Kathrin Röggla: wir schlafen nicht. Frankfurt a. M. 2006.

954 Bereits in den Zeitungsrezensionen zu wir schlafen nicht wurde die Adäquatheit der Gattungsbezeichnung „roman“ verschiedentlich in Zweifel gezogen. Vgl. Susanne Heimburger: Kapitalistischer Geist und literarische Kritik. Arbeitswelten in deutschsprachigen Gegenwartstexten. München 2010, S. 217 f., Anm. 402.

955 Balint: Die Frage literarhistorischer Genrezuordnungen, S. 16. 
auf, stellt aber andererseits die Eigenständigkeit ästhetischer Formungsprozesse deutlich heraus.

Die kritische Stoßrichtung von Rögglas Text leitet sich, wie zu zeigen sein wird, gerade aus dieser künstlerischen Überformung des Recherchematerials ab, die im Folgenden als eine Manifestationsform der Kontrafaktik gedeutet werden soll. Zunächst wird auf den prekären Status der ,Dokumente“ in wir schlafen nicht eingegangen, also auf den Status des realweltlichen Recherchematerials, das Röggla ihrem kreativen Dokumentarismus zugrunde gelegt hat. Anschließend soll ein Überblick über die vielfachen Verfremdungstechniken gegeben werden, die im Roman einen Eindruck der Uneigentlichkeit erzeugen und den Realitätsstatus der fiktionalen Welt ins Wanken geraten lassen. Diese Überlegungen leiten über zu einer Thematisierung der Spannung von mimetisch-realistischen und amimetisch-fantastischen - und in der Folge auch kontrafaktischen - Lesarten von Rögglas Roman. In einem letzten Analyseschritt werden die unsichtbaren Selbsteinschreibungen der Interviewerin im Text, also ihre nur indirekt zu erschließende Anwesenheit und, daran anhängig, ihre eigenen strategischen Interessen als Formen einer autofiktionalen Selbstkommentierung der Autorin Röggla gedeutet, ehe abschließend das politische Projekt von wir schlafen nicht mit Blick auf die formale Anlage des Textes summarisch charakterisiert wird.

\subsubsection{Dokumentarismus ohne Dokumente}

Dem Haupttext von wir schlafen nicht ist die folgende Bemerkung vorangestellt:

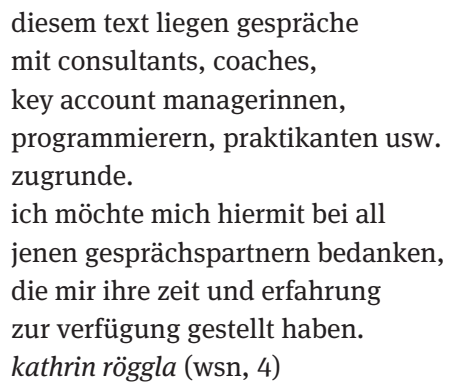

In Form eines faktualen Paratextes gibt die Autorin hier Auskunft über die Herkunft ihres Interviewmaterials. Der „roman“ (wsn, 3) wir schlafen nicht wird damit als dokumentarischer Text markiert. Auf der gegenüberliegenden Seite findet sich dann eine Liste der sieben sprechenden Personen des Textes, inklusive beruflicher Funktion und Alter. Die Begriffe „key account managerin“ und „praktikantin“ finden sich dabei in nur leicht veränderter Form in beiden Tex- 
ten (wsn, 7). Durch ihre druckgrafische Nachbarschaft sowie die partielle lexikalische Überschneidung wird eine Verbindung hergestellt zwischen Rögglas realen Interviewpartnern und den Figuren des fiktionalen Textes.

Die Verbindung von faktualem Paratext und den Figuren von wir schlafen nicht könnte den Eindruck entstehen lassen, Röggla habe für ihren Text lediglich realweltliches Interviewmaterial zusammengetragen. Allerdings wird die Assoziation von realer und fiktionaler Welt bereits auf der beschriebenen Doppelseite durch eine Reihe subtiler Hinweise irritiert. Auffällig ist zunächst die durchgängige Kleinschreibung, sowohl in der Danksagung als auch in der Personenliste. Zur Zeit der Entstehung von wir schlafen nicht hat Röggla die konsequente Kleinschreibung in den meisten ihrer fiktionalen Werke eingesetzt, eher unregelmäßig hingegen in ihren Essays und faktualen Texten. ${ }^{956}$ Dass auch Rögglas paratextuelle Danksagung mit dem Fiktionsmarker der Kleinschreibung versehen wird, weckt erste Zweifel an der Zuverlässigkeit der Materialwiedergabe in wir schlafen nicht. ${ }^{957}$ In eine ähnliche Richtung deutet der ungewöhnliche Zeilenumbruch der Danksagung, der den optischen Eindruck eines Gedichts entstehen lässt. Auffällig ist des Weiteren die Liste der Figuren, die an das dramatis personae-Verzeichnis eines Dramentexts erinnert (auch im Haupttext finden sich diverse Anleihen bei der Dramenästhetik ${ }^{958}$ ). Diese Assoziation zwischen den Figuren von Rögglas Text und den Rollen eines fiktionalen Theaterstücks irritiert die Assoziation der Figuren mit Rögglas realen Interviewpartnern. Angedeutet wird hier, dass in Rögglas Text nicht so sehr reale Einzelpersonen zu Wort kommen, sondern eher Kunstfiguren, die mit ihren realen Vorbildern - wenn man hier überhaupt noch von ,Vorbildern' sprechen kann - nur noch eine unklare Verbindung unterhalten. Als Hinweis auf eine künstlerische Überformung lässt sich ferner der Umstand deuten, dass die Informationen zu den fiktiven Figuren formal nicht einheitlich gestaltet sind: Teilweise werden die wenigen ange-

956 Vgl. Eva Kormann: Wer spricht? Zur, wackeligen“ Sprechposition bei Kathrin Röggla. In: Iuditha Balint / Tanja Nusser / Rolf Parr (Hg.): Kathrin Röggla. München 2017, S. 124-142, hier S. 135.

957 Mit der konsequenten Kleinschreibung in den literarischen Texten knüpft Röggla eigenen Aussagen zufolge an die sprachkritische Tradition der Wiener Gruppe an. Vgl. Röggla / Kasaty: Ein Gespräch mit Kathrin Röggla, S. 262f. Die konsequente Kleinschreibung findet sich in Rögglas jüngeren Texten, etwa in Nachtsendung. Unheimliche Geschichten (2016), nicht mehr.

958 Röggla weist im Interview darauf hin, dass das akustisch-dramatische Element des Textes sich aus dem Sujet ergeben habe: „wir schlafen nicht spielt ja auf einer Messe, und eine Messe ist meist eine akustische Extremsituation, und die habe ich versucht nachzuvollziehen.“ (Röggla: „Literatur ist ja nicht nur Theorie, sondern auch Erfahrung“, S. 50). 
führten Informationen wieder zurückgenommen (,sven, nein, nicht it-supporter, 34"), teils werden Vor- oder Nachnamen weggelassen (,herr gehringer, partner, 48“). Auch fehlt in der Liste - was allerdings erst im Laufe der Lektüre deutlich wird - eine der zentralen Figuren des Textes, nämlich die Interviewerin, die zwar nicht mit eigenen Aussagen in Erscheinung tritt, die aber die anderen Personen allererst zum Sprechen motiviert und die, wie noch zu zeigen sein wird, als organisierende Instanz des gesamten Textes fungiert. Die Liste der Figuren lässt also die formale Sorgfalt, die man von einer faktualen Auflistung realer Personen erwarten würde, auf ostentative Weise vermissen. Irritiert wird die Assoziation von realen und fiktiven Personen schließlich auch dadurch, dass keine nummerische Passung zwischen den beiden Listen besteht: Den sieben Sprecherrollen in wir schlafen nicht liegen offenbar Interviews mit einer größeren, nicht genauer bestimmten Anzahl von Gesprächspartnern zugrunde. ${ }^{959}$

Tatsächlich handelt es sich bei den Figuren, die zu Beginn des Textes genannt werden, weniger um Einzelindividuen, die mit Personen in der realen Welt korrespondieren würden; vielmehr werden hier - wie bereits das „wir“ im Titel wir schlafen nicht andeutet - Kollektivsubjekte dargestellt. ${ }^{960}$ Die Sprecherpassagen des Textes ziehen Sprachmaterial aus Interviews mit verschiedenen Personen zusammen. Die einzelnen, sprechenden Figuren bleiben dabei im Text individuell weitgehend unbestimmt: Ihre Eigennamen werden nur selten genannt, sie sind biografielos und psychologisch kaum greifbar, ja mitunter lässt sich noch nicht einmal entscheiden, wer in einer konkreten Textpassage eigentlich spricht. Als Individuen scheinen sich die Figuren gewissermaßen zu verflüchtigen, wenn sie in einem hyperaktiven Sprechgestus unausgesetzt die Ideologie der New Economy reproduzieren. Röggla selbst bemerkt hierzu: „Der Redezwang meiner Figuren, der Zwang zur permanenten Selbstdarstellung, zum Selbstentwurf, wirkt sozial gesteuert und sozial hervorgebracht. Er ist absolut unindividuell."961 Just ihre weitgehende Anonymität und fehlende Individualität exponiert diese Figuren als

959 Zum Rechercheprozess von wir schlafen nicht bemerkt Röggla: „Ich habe um die 25 längere Interviews (von eineinhalb bis vier Stunden) mit Consultants, Coaches, Programmierern, Journalisten geführt und ca. 15 kürzere, habe viel zum Thema Arbeit, Arbeitsbegriff gelesen.“ (Kathrin Röggla / Karin Cerny: Kathrin Röggla. E-Mail-Interview. Quelle: http://www.literatur haus.at/index.php?id=5246 (Zugriff: 27.07.2021)).

960 Vgl. Balint: Die Frage literarhistorischer Genrezuordnungen, S. 24.

961 Röggla: Essenpoetik, S. 16. Bemerkenswert ist in diesem Zusammenhang, dass die Frage der Persönlichkeitsrechte bei der Bearbeitung der Interviews Röggla zufolge weder für den Verlag noch für die interviewten Personen eine Rolle gespielt habe. Negative Reaktionen habe es allerdings vonseiten der Unternehmensberatungsfirmen McKinsey und Boston Consulting gegeben. Diese unterschiedliche Rezeption von individuell-persönlicher oder aber strukturellunternehmerischer Seite kann durchaus als Indikation für den Erfolg des politisch-ästheti- 
exemplarische Vertreter der Welt der Unternehmensberatung und, davon abgeleitet, als „Einzelrepräsentanten“ allgemeinerer Veränderungen in Arbeitswelt und Gesellschaft der Gegenwart: ${ }^{962}$ Die Unternehmensberater fungieren, wie Susanne Heimburger bemerkt, in wir schlafen nicht als „Wächter über die Einhaltung des allgemeinen Effizienzgebots““.963 Sie verweisen damit auch jenseits des eigenen, engeren Einflussbereichs auf die Entwicklungstendenz einer Gesellschaft, in der das ,unternehmerische Selbst' (Ulrich Bröckling) zusehends zum Leitbild avanciert $^{964}$, die also immer mehr von neoliberalen Imperativen der Effizienzsteigerung, Beschleunigung und Selbstoptimierung erfasst wird.

Röggla übernimmt das von ihr zusammengetragene Interviewmaterial also nicht unverändert in den Text, sondern überformt und strukturiert es erkennbar. Neben der bereits erwähnten Komprimierung und Verteilung auf sieben Sprecher fällt die fast durchgängige Verwendung des Konjunktivs auf. So wie die konsequente Kleinschreibung in Rögglas Texten ein Irritationsmoment darstellt, das bereits optisch auf die Medialität und Vermittlungsleistung (geschriebener) Sprache hindeutet, so wird auch durch die grammatikalische Form des Konjunktivs der vermittelte Status der Aussagen betont. Anhand dieses Verfahrens wird in wir schlafen nicht der Jargon der Unternehmensberatung, der ja ursprünglich darauf angelegt ist, sich selbst als pragmatisch, nüchtern-geschäftlich und vor allem realitätsnah zu präsentieren, auffallend verfremdet. Er wird damit als eine Form des Sprechens erkennbar, die einem spezifischen Kontext angehört,

schen Projekts von wir schlafen nicht betrachtet werden. Vgl. Röggla: Im Moment durchkreuze ich den Feldbegriff mit meiner Arbeit, S. 173f.; dies.: „Literatur ist ja nicht nur Theorie, sondern auch Erfahrung“, S. 50.

962 Iuditha Balint hält fest: „So reagiert auch Rögglas Roman auf die Veränderungen der Arbeitswelt, indem er seine Figuren nicht als vom Wirtschaftssystem unterdrückte Gruppe, sondern als Einzelrepräsentanten des Systems inszeniert, an denen sowohl die motivationale als auch die Sinngebungsdimension der Entgrenzung und Subjektivierung der Arbeit durchaus ablesbar sind.“ (Iuditha Balint: Erzählte Entgrenzungen. Narrationen von Arbeit zu Beginn des 21. Jahrhunderts. Paderborn 2017, S. 82).

963 Heimburger: Kapitalistischer Geist und literarische Kritik, S. 219.

964 Vgl. Ulrich Bröckling: Das unternehmerische Selbst. Soziologie einer Subjektivierungsform. Frankfurt a. M. 2007. Auf Bröcklings Studie nimmt Röggla explizit Bezug in: Die falsche Frage, S. 12, 79f. Bröckling schließt seinerseits an die Studie Der neue Geist des Kapitalismus von Luc Boltanski und Ėve Chiapello an. Vgl. Bröckling: Das unternehmerische Selbst, S. 260-266. Auch Luc Boltanski und Ève Chiapello betrachten den „Managementdiskurs“ als einen paradigmatischen Diskurs der Arbeitswelt der 1990er Jahre, wenn sie „[d]ie Managementliteratur als normative[n] Rahmen des Kapitalismus“ analysieren (Luc Boltanski / Ėve Chiapello: Der neue Geist des Kapitalismus. Konstanz 2006, S. 91). 
mit seinen eigenen, häufig unausgesprochenen Regeln und unhinterfragten Interessen. Aus diesem pragmatischen Kontext herausgelöst, verlieren die impliziten Normen, die diese Sprachpraxis regulieren, ihre Selbstverständlichkeit. Ein Satz etwa wie „aber auch er finde es ganz schön absurd, das ganze wording“ (wsn, 13), dekonstruiert sich gewissermaßen selbst.

Die formale Überformung des Textes geht aber noch weit über den Einsatz des Konjunktivs hinaus: Selbst wenn man die konjunktivischen Passagen des Textes nämlich in den Indikativ rückübertragen wollte, würde der Text an vielen Stellen immer noch derart viele formale Auffälligkeiten aufweisen - Rhythmisierungen, Wiederholungen, Zusammenrückungen widersprüchlicher Aussagen, offensichtliche Unterdrückungen von Interview-Fragen, ein Spiel mit sprachlichen Mehrdeutigkeiten etc. -, dass die Option, hier werde reales Interviewmaterial eins zu eins wiedergegeben, zuverlässig ausgeschlossen werden kann. Diese offenkundige Verfremdung sowie das Neuarrangement des Interviewmaterials wirken notwendigerweise auf den dokumentarischen Status von Rögglas Text zurück, insofern bei der Lektüre unklar bleibt, inwieweit man es hier überhaupt noch mit authentischem Sprachmaterial zu tun hat. ${ }^{965}$ Unverkennbar ist lediglich der Umstand, dass eine künstlerische Bearbeitung stattgefunden hat. Wie weit diese geht, ob und in welchem Maße Röggla eigenständig Textpassagen hinzugefügt hat und inwieweit einzelne Aussagen durch Rekontextualisierung ihren ursprünglichen Sinn verloren haben, lässt sich anhand des manifesten Textes nicht mehr entscheiden. Anders als im Falle etwa der Dokumentardramen von Heinar Kipphardt sind die Dokumente, auf die Röggla beim Verfassen ihres Werkes zurückgegriffen hat, nicht öffentlich zugänglich, sodass auch kein Detailabgleich zwischen faktualer Quelle und fiktionaler Bearbeitung möglich ist. wir schlafen nicht kann mithin gerade nicht, wie Holger Noltze in der FAZ-Rezension zu Rög-

965 Auch Natalie Moser hält fest, dass die „Verfremdung“ des „Sprachmaterials“ „während der Lektüre nicht ermessen werden [kann]“ (Natalie Moser: Echtzeit-Fiktion. Zur Funktion des Protokolls und der Übung in Kathrin Rögglas die zuseher (2010). In: Iuditha Balint / Tanja Nusser / Rolf Parr (Hg.): Kathrin Röggla. München 2017, S. 161-180, hier S. 172). Dag Kemser muss also widersprochen werden, wenn er behauptet, dass Röggla in wir schlafen nicht ,auf fiktive Elemente komplett verzichtet [habe] und [dass] der Stücktext sich vollständig aus dokumentarischem Sprachmaterial zusammensetzt und zwar aus Interviews, die sie in der Unternehmensberaterbranche selbst geführt hat.“ (Dag Kemser: Neues Interesse an dokumentarischen Formen: Unter Eis von Falk Richter und wir schlafen nicht von Kathrin Röggla. In: Hans-Peter Bayerdörfer (Hg.): Vom Drama zum Theatertext? Zur Situation der Dramatik in Ländern Mitteleuropas. Tübingen 2007, S. 95-102, hier S. 100). 
glas Text behauptet, als ein „Originaltonhörspiel zum Lesen“966 angesehen werden. Vielmehr hat man es hier mit einem quasi-dokumentarischen Kunstprodukt zu tun, dessen ästhetisches Kalkül gerade darin besteht, den Grad der eigenen Künstlichkeit im Unklaren zu lassen.

Inwiefern können nun aber die primär formalen Verfremdungsverfahren, die Röggla in wir schlafen nicht einsetzt, als Manifestationsformen der Kontrafaktik angesehen werden? Abweichungen von propositional formulierbarem Faktenwissen, wie sie etwa für die Kontrafaktik im Genre der Alternate History charakteristisch sind, finden sich in Rögglas Text nicht. Die Definitionskriterien der Kontrafaktik jedoch, dass nämlich eine signifikante Variation realweltlichen Faktenmaterials in einem fiktionalen Medium vorliegen muss, erfüllt Rögglas Text durchaus: Dass es sich bei wir schlafen nicht um einen fiktionalen Text handelt, wird bereits durch die Genrebezeichnung „roman“ deutlichgemacht. Auch wird im Text realweltliches Faktenmaterial in Form dokumentarischen Materials einbezogen - die Interviews nämlich, die Röggla mit Vertretern der New Economy geführt hat -, und dieses Faktenmaterial wird auch variiert. Nur handelt es sich hier, soweit dies für den Leser erkennbar ist, eben nicht um eine inhaltliche Variation, also eine Variation auf der Ebene der histoire, sondern um eine formale Variation auf der Ebene des discours. Eine solche primär formalästhetische Variation realweltlichen Faktenmaterials ließe sich als ,formale Kontrafaktik' bezeichnen, als eine Ausprägung der Kontrafaktik also, die weniger auf der Gegenüberstellung zweier einander widersprechender Aussagen beruht als vielmehr auf dem Eindruck sinnlicher Irritation (wie er sich im pikturalen Bereich auch bereits bei Betrachtung der übertriebenen Farben der Coverabbildung von wir schlafen nicht einstellen mag). Dieser Eindruck führt nicht zu einem klaren Urteil à la „Dies ist (realweltlich) unzutreffen.“ oder „Das können sie nicht gesagt haben.“, sondern eher zu einem je ne sais quoi etwa des Sinns: „Auch wenn diesem Text Interviews mit realen Personen zugrunde liegen - so können sie nicht gesprochen haben.“967

Formale oder auch sinnliche Spielarten der Realitätsvariation schließen nun eine Eindeutigkeit der Abweichung keineswegs aus. Wenn etwa auf einem Foto der Nachthimmel komplett orange erschiene, wäre es offensichtlich, dass hier von der Realität abgewichen wird. Rögglas Ästhetik zielt nun aber gerade darauf ab, die Möglichkeit solcher eindeutiger Unterscheidungen zwischen

966 Holger Noltze: Klettern im Kontrollgebirge. Ohne Auszeit: Kathrin Röggla nimmt die Wirtschaft zu Protokoll. In: Frankfurter Allgemeine Zeitung, 07.04.2004.

967 Mit Nelson Goodman ließe sich in diesem Kontext festhalten: „nicht nur sagend, auch zeigend kann man Welten erschaffen.“ (Goodman: Weisen der Welterzeugung, S. 32). 
Faktenwiedergabe und Faktenvariation zu unterminieren. Zwar ist offenkundig, dass der Text als Ganzes das ihm zugrundeliegende Interviewmaterial variiert. Ob und in welchem Maße eine einzelne Textpassage allerdings eine Faktenvariation miteinschließt, lässt sich nicht eindeutig entscheiden - nicht nur deshalb, weil die originalen Interviewaussagen unzugänglich sind, sondern auch, weil die reale Unternehmensberatung selbst mit hochgradig fiktiven oder virtuellen Größen operiert und der Jargon der Unternehmensberater Formulierungen umfasst, die kaum noch einen direkten Rückschluss auf die Realität erlauben. Mit seinen Verfremdungsverfahren respektive durch seinen Einsatz formaler Kontrafaktik bringt wir schlafen nicht mithin nicht eindeutiges Faktenmaterial in Spannung zu dessen Variation innerhalb einer fiktionalen Welt. Vielmehr deutet die formale Kontrafaktik hier textübergreifend auf eine Differenz zwischen dem Faktenmaterial und seiner künstlerischen Bearbeitung hin, wobei das Ausmaß dieser Bearbeitung sich im Einzelnen eben nicht zuverlässig eruieren lässt. Genau diese Verunsicherung bezüglich der Frage, ob man es an einer einzelnen Textstelle noch mit faktischem Dokumentarismus oder bereits mit einer kontrafaktischen Realitätsvariation zu tun hat, korrespondiert in wir schlafen nicht mit der „Derealisierungsmaschinerie“968 des dokumentierten Diskurses selbst: Die Unsicherheit hinsichtlich des Verhältnisses von Diskurs und Realität, wie sie sich mit Blick auf die Sphäre der realen Unternehmensberatung einstellen mag, wird im ästhetischen Bereich durch die Unsicherheit hinsichtlich des Verhältnisses von fiktionaler und realer Welt aufgegriffen.

\subsubsection{Produktion von Uneigentlichkeit}

Wie in allen Texten Rögglas kommen auch in wir schlafen nicht vielfältige ästhetische Verfremdungstechniken zum Einsatz. Diese führen zu einer Irritation von Genreerwartungen, zur Vermischung von Realität und Erfindung und zu Verunsicherungen hinsichtlich des ontologischen Status der fiktionalen Welt. Insgesamt ließe sich der Effekt von Rögglas ästhetischen Verfahren als ,Produktion von Uneigentlichkeit' beschreiben: Kategoriale Grenzen werden verwischt und Annahmen über das Wesen der Realität werden unterlaufen. Da diese Produktion von Uneigentlichkeit einerseits Einfluss auf den Fiktionsstatus einzelner Elemente hat inklusive ihrer potentiellen Zuordnung zum Bereich der Kontrafaktik - und ande-

968 Röggla: Die falsche Frage, S. 75. 
rerseits für eine politische Bewertung von wir schlafen nicht zentral ist, seien im Folgenden einige dieser Verfremdungstechniken exemplarisch erläutert.

wir schlafen nicht ist in 33 Kleinkapitel unterteilt, welche nach Themen geordnet Äußerungen von sieben Sprechern zu unterschiedlichen Aspekten der Arbeitswelt umfassen. Die klassischen Ordnungsmomente des realistischen Romans, also eine kontinuierliche Handlung und ein Protagonist, der eine psychische oder biografische Entwicklung durchläuft, fehlen hier. In wir schlafen nicht erfährt keine einzelne Figur, sondern allenfalls das ,Kollektivsubjekt' Unternehmensberatung eine Transformation. Die zunächst inkommensurabel erscheinende Textsammlung weist in der Gesamtschau nämlich durchaus eine dramatische Kurve, genauer: eine negative Steigerungsdynamik auf. Im Fortgang der Lektüre drängt sich immer stärker der Eindruck auf, dass die dargestellten Sprech-, Lebens- und Arbeitsweisen dem eigenen Anspruch auf permanente Produktivitätssteigerung keineswegs entsprechen. ${ }^{969}$ Eine Arbeits- und Wirtschaftsstruktur jedoch, die nur noch durch unausgesetzte Selbstbestätigung Oberwasser behält, droht an den Klippen des Realen seien diese nun persönlich-psychologischer oder ökonomischer Natur - zu kentern und dabei die Individuen, welche die Dogmen eines ungebremsten Neoliberalismus beständig reproduzieren, mit in den Abgrund zu reißen. ${ }^{970}$

Im Durchgang durch die Kapitel dringt der Leser in immer tiefere, immer weniger öffentlich einsehbare und hinsichtlich ihres Realitätsstatus immer dubiosere, ja teils sogar unheimliche Bereiche des Managements vor. Während einige der ersten Kapitel mit Titeln wie „die messe“, „betrieb“ oder „harte bwl“ noch auf recht erwartbare Weise mit der Sphäre der Unternehmensberatung korreliert sind, thematisieren die Kapitel in der zweiten Hälfte des Buches mit wachsender Explizitheit die körperlichen und seelischen Belastungen sowie die Langzeitfol-

969 In ähnlicher Weise hält Ernest Schonfield fest: „There is a sense of fatalism in wir schlafen nicht, as Röggla's characters seem doomed to rehearse the commercial language that imprisons them." (Ernest Schonfield: Business Rhetoric in German Novels. From Buddenbrooks to the Global Corporation. New York 2018, S. 160).

970 Die Thematisierung der beruflichen Gefährdungen auch noch der höherqualifizierten Arbeitskräfte unterscheidet gegenwärtige Behandlungen des Themas Arbeit in der Literatur von älteren literarischen Auseinandersetzungen mit demselben Thema, etwa in der Angestelltenliteratur der Weimarer Republik oder der sogenannten ,Literatur der Arbeitswelt der 1960er und 1970er Jahren (Bitterfelder Weg und Werkkreis). Ulrike Vedder hält fest, dass „das literarische Interesse heute zumeist einer technisch hochgerüsteten Dienstleistungsbranche mit hochqualifizierten, aber stets vom Überflüssigwerden bedrohten Mitarbeiter/innen [gilt].“ (Ulrike Vedder: Arbeitswelten und Ökonomie: Zur literarischen Kritik der Gegenwart. In: Corinna Caduff / Ulrike Vedder (Hg.): Gegenwart schreiben. Zur deutschsprachigen Literatur 2000-2015. Paderborn 2017, S. 63-73, hier S. 64). 
gen des beschriebenen Arbeitsalltags, etwa in Kapiteln wie „wir schlafen nicht“, „schock“, „koma“ oder „gedächtnis“. Zum Teil deuten die Kapitelüberschriften gar auf die Versuche einer Flucht aus der Sphäre der Unternehmensberatung hin: in „rauskommen“, „exit-szenarium“ oder im letzten Kapitel „wiederbelebung (ich)“. Auch verdichten sich im Fortgang des Textes die Anzeichen dafür, dass die Sphäre der hyperkapitalistischen Arbeitswelt von den Sprechern selbst, die doch gerade die subjektiv treibenden Kräfte der New Economy bilden, kaum mehr verstanden, geschweige denn beherrscht werden kann. So verschwinden Menschen auf unerklärliche Weise aus dem Unternehmen (vgl. wsn, 152-155); gleichsam im Augenwinkel der Erzählung ereignet sich ein Suizid (vgl. wsn, 214); und ein Notfall auf der Messe, mit panisch dem Ausgang zuflüchtenden Menschen, kann weder objektiv expliziert noch subjektiv verarbeitet werden (vgl. wsn, 182f.).

Überhaupt erweist sich die Weltwahrnehmung der Sprecher im Verlauf des Textes als zusehends unzuverlässig. Je weiter der Text voranschreitet, umso mehr häufen sich Situationen der Überforderung, des subjektiven Unverständnisses oder des schieren Gruselns. Hinzu kommt die wiederholte Erwähnung von Wahrnehmungsstörungen (vgl. wsn, 129, 180), Alkoholismus (vgl. wsn, 76f., 177) und Tablettenabhängigkeit (vgl. wsn, 150). Hierdurch werden einerseits die enormen körperlichen und seelischen Belastungen der beschriebenen Arbeitsform erkennbar: Bereits der Titel wir schlafen nicht verweist ja auf die kollektive Verweigerung gegenüber einem körperlichen Grundbedürfnis. Andererseits wecken diese Eingeständnisse kognitiver Einschränkungen aber auch Zweifel an der Zuverlässigkeit der Sprecheraussagen: Durch die Unzuverlässigkeit der Wahrnehmung gerät die fiktionale Welt selbst ins Wanken, die ja nicht über den Bericht eines souveränen Erzählers, sondern einzig über die Äußerungen der Figuren vermittelt ist.

Mit seinen ästhetischen Verunsicherungsverfahren reagiert wir schlafen nicht auf die, wenn man so will, reale Irrealität seines Gegenstandes: Die Sphäre der Unternehmensberatung zeigt nämlich bereits an und für sich in zahlreichen ihrer Teilaspekte Tendenzen zur Virtualisierung, Derealisierung und strategischen Narrativierung. Erwähnt wird im Text etwa die Empfehlung zur Entlassung hunderter Mitarbeiter, wobei die Unternehmensberater diese Menschen persönlich nie zu Gesicht bekommen (vgl. wsn, 37). Erwähnt werden ferner das betriebswirtschaftliche, virtuelle Zahlenkalkül, das reale Personalentscheidungen nach sich zieht (wsn, 37), sowie der Jargon der Unternehmensberatung, der von Außenstehenden kaum noch verstanden werden kann, wiewohl er für diese Außenstehenden mitunter sehr reale Wirkungen zeitigt (wsn, 10f., 73). Teils werden faktengestützte Informationen gar durch bloße Gerüchte ersetzt: „man erinnert sich ja mehr an gerüchte als an tatsachen, weil gerüchte viel beliebter seien, ,weil sie einfach die besseren geschichten sind'“" (wsn, 195) Indem hier ästhetische Kriterien an die Stelle von Wahrheitskriterien treten, 
wird zugleich eine Parallele zwischen den Abläufen im Bereich der Unternehmensberatung und der Funktionsweise von Rögglas Text hergestellt, der zwar einerseits auf dokumentarisches Material - also auf „tatsachen“ - zurückgreift, dieses Material aber nicht für sich selbst sprechen lässt, sondern es nach ästhetischen Gesichtspunkten arrangiert. In beiden Fällen sind die Wirkungen dieses Arrangements durchaus real: Im Einflussbereich der Unternehmensberatung können bloße Gerüchte schwerwiegende wirtschaftliche Konsequenzen nach sich ziehen; und im Falle Rögglas liegt eben der künstlerische Text wir schlafen nicht vor. Auch kann in beiden Fällen nicht mehr zuverlässig auf die ,rohen` Fakten rückgeschlossen werden, also auf die Tatsachen in einem Stadium vor ihrer diskursiven Bearbeitung und ästhetischen Überformung. Wie die Welt ,eigentlich aussieht - und ob diese Frage hinsichtlich der hier in Frage stehenden Phänomene überhaupt noch sinnvoll zu stellen ist -, bleibt ungeklärt.

Gelegentlich wird der schwankende Realitätsstatus der fiktionalen Welt in Form metafiktionaler Aussagen im Text selbst thematisiert. Als kompaktes Beispiel kann die folgende Passage dienen: ,ja, sie solle lieber etwas machen, das realistisch sei, ,auch wenn das heute gar nicht mehr zu machen ist', wie ihr onkel, der tischler, immer sage.“ (wsn, 157) Auf für Röggla charakteristische Weise wird hier der Begriff „realistisch“ mehrfach überkodiert. Erstens bezieht er sich in einem alltagssprachlichen Sinne auf die Pragmatik der Berufswahl. Anhand der Berufsbezeichnung „tischler“ wird hier zweitens auf den Bereich materiell-physischer, also ,realer' Produktion verwiesen, an welchem die New Economy - und, so könnte man hinzufügen: auch die Literatur - gerade nicht mehr partizipiert. Drittens schließlich lässt sich der Begriff „realistisch“ als Verweis auf den (prekären) ästhetischen Status von Rögglas Text selbst verstehen, in welchem der Versuch unternommen wird, eine Form des Realismus zu entwickeln, welche der virtuellen, in ihren Wirkungen aber sehr realen Sphäre der Unternehmensberatung angemessen ist. Wenn in der zitierten Textpassage also betont wird, dass ,heute etwas Realistisches gar nicht mehr zu machen sei', so bedeutet das nicht nur, dass es unter den gegebenen Wirtschaftsbedingungen schwierig ist, eine Festanstellung in einem zukunftsträchtigen Wirtschaftszweig zu ergattern; es heißt eben auch, dass ein klassischer Realismus die hochgradig virtuelle Welt der Unternehmensberatung nicht mehr adäquat zu fassen vermag.

Der Herausforderung, „etwas [zu] machen, das realistisch sei, ,auch wenn das heute gar nicht mehr zu machen ist““ (wsn, 157), begegnet Röggla dadurch, dass sie in ihren Text Widersprüche, Formen der Hybridisierung und Realitätsstörungen einbaut, die sich ihrerseits mit der Funktionslogik der hochgradig virtuellen, dematerialisierten Welt der Unternehmensberatung parallelisieren lassen. „Durch diese formalen Widersprüche“, so bemerkt Susanne Heimburger, werde auch „die Wirklichkeitsfiktion, die normalerweise mit dem Dokumentarischen verbunden ist, un- 
terlaufen.“971 Angesichts einer solchen Störung der ,Wirklichkeitsfiktion“ muss zwar der Anspruch, das Faktenmaterial unmittelbar greifen und wiedergeben zu können - ein Anspruch, den konventionellere Formen des Dokumentarismus durchaus erheben - fallengelassen werden. Genau diese Unfähigkeit zu einem ,faktischen' Dokumentarismus rückt den künstlerischen Text allerdings in Parallele zu den vorgängigen Virtualisierungstendenzen der Unternehmensberatung selbst. Das ästhetische Kalkül von wir schlafen nicht besteht paradoxerweise gerade darin, einen faktenbasierten Dokumentarismus in seinem Scheitern vorzuführen, um damit auf einer höheren Ebene die Funktionslogik eines Gesellschaftsbereichs zu dokumentieren - respektive ästhetisch erfahrbar zu machen -, dessen eigener $\mathrm{Zu}$ griff auf die sogenannte reale Welt längst prekär geworden ist.

\subsubsection{Die Gespenster des Kapitalismus: reale Fantastik versus Realfantastik}

Den Roman wir schlafen nicht hat Röggla als „eine Art Gespenstergeschichte [...], oder besser gesagt, eine Zombiestory“972 bezeichnet. Wie überall in Rögglas Werk wird auch in wir schlafen nicht der Verweis auf Begriffe aus dem Assoziationsbereich der Fantastik verwendet, um den prekären Realitätsstatus der zur Diskussion stehenden Phänomene anzudeuten. Insbesondere gegen Ende des Textes wird die substanzlose, gleichzeitig aber unendlich getriebene Welt der Unternehmensberatung mittels einer immer deutlicher um sich greifenden Metaphorik des (Un-)Toten und Gespenstischen charakterisiert (vgl. etwa wsn, 201). Das Gespenstische verweist dabei zunächst auf den prekären Status des Somatischen sowie des Materiellen in der New Economy: Einerseits werden die Figuren von wir schlafen nicht durch die kontinuierliche Verweigerung gegenüber körperlichen Grundbedürfnissen zusehends unmenschlich; sie geraten damit gewissermaßen selbst zu Geistern oder gar zu Zombies, nähern sich also einer Klasse fantastischer Wesen an, die sich definieren lässt als „Tote, die nicht schlafen“. 973 Andererseits eignet auch den ökonomischen Strukturen, in welche die Unternehmensberater verwickelt sind und auf die sie ihrerseits einzuwirken versuchen, eine geisterhaft-unwirkliche Dimension: Finanzspekulationen, Wirtschaftsprognosen und die Informationsökonomie digitaler Prozesse unterhalten nur

971 Heimburger: Kapitalistischer Geist und literarische Kritik, S. 230.

972 Röggla: Essenpoetik, S. 33.

973 Heimburger: Kapitalistischer Geist und literarische Kritik, S. 226. 
mehr eine sehr unklare Verbindung zur Realwirtschaft und den Lebensrealitäten einzelner Menschen.

Nicht zuletzt greift Röggla mit dem Begriff des Gespenstes eine Zentralmetapher der antikapitalistischen Ideologiekritik auf, die prominent im ersten Satz des Kommunistischen Manifests von Karl Marx und Friedrich Engels eingeführt wurde: „Ein Gespenst geht um in Europa - das Gespenst des Kommunismus.“974 Im 20. Jahrhundert wurde diese Metapher unter anderem von Jacques Derrida, im Titel seines Werkes Marx' Gespenster ${ }^{975}$, sowie in jüngerer Zeit etwa von Joseph Vogl in seinem Buch Das Gespenst des Kapitals ${ }^{976}$ aufgegriffen. Mit ihrer ,gespenstischen' Darstellung der New Economy schließt Röggla somit an eine Linie der Kapitalismuskritik an, welche gerade die Unheimlichkeit, Irrationalität und subjektive Unintegrierbarkeit ökonomischer Prozesse hervorhebt.

Als Beispiel einer solchen unheimliche Wirksamkeit der Wirtschaftsprozesse lässt sich ein Ausschnitt aus dem Kapitel harte bwl anführen:

„unterschiedliche unternehmenskulturen“ seien genauso wie „harte bwl“ schimären. aber so was behalte man, wie gesagt, besser für sich und sehe sich lieber genauer die problemlage an. „natürlich gibt es zahlen und fakten, natürlich gibt es irgendwo einen betriebswirtschaftlichen hintergrund“, aber bis man „harte bwl“ wieder vorfinden könne, müsse man schon eine weile graben.

(wsn, 56)

Der Rekurs auf vermeintlich unzweideutige Fakten der realen Welt - auf Unternehmenskulturen und BWL - wird hier zur strategischen Illusion erklärt, eine Illusion allerdings, deren illusorischer Charakter gerade nicht thematisiert werden darf. Gleichwohl unterhalten, so wird behauptet, die hier exponierten Phänomene durchaus eine Verbindung zur Realität - „irgendwo“ gibt es „einen betriebswirtschaftlichen hintergrund“ -; allerdings sei die genaue Natur dieser Verbindung eben nicht problemlos erkennbar. Bei genauer Lektüre der zitierten Passage fällt ferner auf, dass der Begriff „harte bwl“ hier in zwei unterschiedlichen Bedeutungen gebraucht wird: Einerseits wird „harte bwl“ mit wirtschaftlichen „zahlen und fakten“ korreliert. Andererseits jedoch soll es sich dabei um

974 Karl Marx / Friedrich Engels: Das Kommunistische Manifest. Mit einer Einleitung von Eric Hobsbawm. Hamburg 1999, S. 43.

975 Jacques Derrida: Marx’ Gespenster. Der Staat der Schuld, die Trauerarbeit und die neue Internationale. Frankfurt a. M. 1995, S. 16.

976 „Politische Ökonomie hat seit jeher eine Neigung zur Geisterkunde gehegt und sich mit unsichtbaren Händen und anderem Spuk den Gang des Wirtschaftsgeschehens erklärt. Dies ist wohl einer gewissen Unheimlichkeit ökonomischer Prozesse geschuldet, in denen zirkulierende Objekte und Zeichen einen gespenstischen Eigensinn entwickeln. [...] Das ,Gespenst des Kapitals‘ erscheint [...] als Chiffre für jene Kräfte, von denen unsere Gegenwart ihre Gesetze empfängt.“ (Joseph Vogl: Das Gespenst des Kapitals. Zürich 2010, S. 7). 
eine „schimäre“ handeln. Mithin ist „harte bwl“ - in offenkundigem Widerspruch zu den Implikationen der Härte-Metapher - materiell gerade nicht mehr eindeutig bestimmbar, sondern steht vielmehr zwischen Wirklichkeit und Unwirklichkeit - und erfüllt damit just die Definition des Gespenstischen als einer Sphäre zwischen An- und Abwesenheit.

Entsprechend konsequent ist es, wenn „harte bwl“ an einer späteren Stelle des Buches mit dem Bereich des Unheimlichen assoziiert wird:

und? habe sie jemand gefunden, den sie verantwortlich machen können?

nein, wieder niemand, den man verantwortlich machen kann.

wieder keiner, den man doppelt sehen kann?

nein, auch da ist nur harte bwl im gang.“ (wsn, 62)

Die Unmöglichkeit, wirtschaftliche Entscheidungen mit persönlich-individuellen Verantwortlichkeiten zu verbinden, wird hier einerseits durch einen Verweis auf „harte bwl“ begründet. Zugleich aber klingt in der zunächst unverständlichen Rede vom „doppelt sehen“ das fantastische Motiv des Doppelgängers an, wie es Sigmund Freud prominent in seinem Aufsatz Das Unheimliche (1919) analysiert hat. ${ }^{977}$ Gestützt wird diese Assoziation mit dem Bereich der Fantastik durch die potenziell doppeldeutige Formulierung „im gang“: Diese kann einerseits in gebräuchlicher idiomatischer Bedeutung, also im Sinne von ,etwas geht vor sich“, verstanden werden (wobei hier eine zusätzliche Anknüpfung an das Thema der Verantwortungslosigkeit hergestellt würde, lässt sich doch für etwas, das lediglich ,im Gange، ist, kein handelndes Subjekt angeben). Andererseits kann die Formulierung aber auch als lokale adverbiale Bestimmung gedeutet werden, wenn nämlich das ,im gang“ befindliche Objekt (oder Subjekt?) die ,harte bwl‘ selbst wäre. Plausibel schließt diese Doppel-Deutung an andere Passagen von wir schlafen nicht an, in denen die Unternehmensberatung selbst als unheimliches Subjekt charakterisiert wird: etwa wenn über die McKinsey-Berater gesagt wird ,,,brrrt, der mckinseyking geht wieder einmal über die flure, brrrrt‘ da schüttele es sie“ (wsn, 42).

Insgesamt bietet Röggla, wie Natalie Moser bemerkt, „ihrer Leserschaft nicht nur eine dokumentarische und ,realistische‘, sondern auch eine fantastische Lesart ihrer Texte an[...]“. ${ }^{978}$ Dabei kann die ,fantastische Lesart" von Rögglas Texten nicht auf den bloßen Gebrauch von Metaphern aus dem Bereich der Fantastik beschränkt werden (allein als Metaphern verstanden wären die fantastischen Elemente für die Ontologie der fiktionalen Welt letztlich ohne

977 Sigmund Freud: Das Unheimliche. In: Ders.: Studienausgabe Bd. IV: Psychologische Schriften. Frankfurt a. M. ${ }^{11}$ 2012, S. 241-274, hier S. 257-259.

978 Moser: Echtzeit-Fiktion, S. 177. 
Belang $\left.{ }^{979}\right)$. Vielmehr scheint die fiktionale Welt in wir schlafen nicht mitunter ganz real in den Bereich des Fantastische, Unwirklichen oder Unheimlichen hinüberzuspielen. Stellenweise wissen die Sprecher nicht mehr, ob sie noch am Leben oder bereits tot sind: „mit ihrem 42. geburtstag würde sie schon noch rechnen, auch wenn der schon hinter ihr liege“ (wsn, 185, vgl. auch wsn, 200). Teils ziehen die Sprecher auch in Erwägung, bereits zu Gespenstern geworden zu sein: ,aber ob sie immer mehr zum gespenst werde, wisse sie nicht. wer solle das auch entscheiden [...] sie könne nur sagen: ,wie das gespenst immer mehr stimmt, zu dem man verdonnert wurde [...]““ (wsn, 197). Passagen wie die folgende schließlich stellen einer lediglich metaphorischen - und mithin potenziell realistischen - Lesart beträchtliche Hindernisse in den Weg:

die key account managerin: was werde hier zum verschwinden gebracht? sie würde sagen, die praktikantin (lacht), aber vielleicht habe es die auch nie gegeben. nein, im ernst, sie habe es ja von einer grafikerin gehört. eines morgens sei eine kollegin in der dusche verschwunden, aus der sie nie zurückgekehrt sei. und auch eine kollegin vom handelsblatt habe ihr so geschichten erzählt, geschichten, in denen der eine oder andere verschwunden sei.

(wsn, 153)

Es bleibt bei dieser und ähnlichen Passagen unklar, ob man es hier eher mit Phänomenen zu tun hat, die zwar vordergründig fantastisch anmuten, schlussendlich aber noch der derealisierten Wirklichkeit der Unternehmensberatung zugerechnet werden können - oder aber ob hier tatsächlich fantastische Elemente in die Diegese eingebraut werden, man es also mit Aspekten jener „Zombiestory“980 zu tun hat, zu der Röggla ihren eignen Aussagen nach das Faktenmaterial der Unternehmensberatung in wir schlafen nicht arrangiert hat. Der Text scheint genau auf die Erzeugung dieser Unentscheidbarkeit zwischen Realfantastik - also einem fantastischen Anschein der Realität selbst - und realer Fantastik - realen fantastischen Ereignissen innerhalb der fiktionalen Welt - hin kalkuliert zu sein. Wollte man sich nur für die letzte Interpretationsoption entscheiden, so würde in wir schlafen nicht paradoxerweise eine Form des fantastischen Dokumentarismus praktiziert, also eine Überblendung von faktischen mit fantastischen Realitätsbezügen - was notwendigerweise zur Folge hätte, dass man es mit kontrafaktischen Elementen zu tun hätte, einfach deshalb, weil faktische Einzelinformationen über die reale Welt per definitionem niemals zugleich fantastisch sein können. Im Falle einer Überblendung von Faktik und Fantastik innerhalb der fiktionalen Welt ergibt

979 Zurecht betonen die Herausgeber des Bandes Gespenster. Erscheinungen - Medien - Theorien: „Wo Gespenster eindeutig als Metapher gebraucht werden, wird nicht an Gespenster geglaubt.“ (Baßler / Gruber / Wagner-Egelhaaf: Einleitung, S. 11).

980 Röggla: Essenpoetik, S. 33. 
sich notwendigerweise eine kontrafaktische Realitätsvariation. ${ }^{981}$ Ließe sich eine solche kontrafaktische Realitätsvariation qua Fantastik in wir schlafen nicht tatsächlich eindeutig feststellen, so hätte man es hier nicht nur mit Ausprägungen der oben beschriebenen formalen Kontrafaktik, sondern sogar mit eindeutig fantastisch-kontrafaktischen Elementen zu tun.

Genau eine solche, eindeutige Interpretationsentscheidung lässt der Text allerdings nicht zu: Was wie eine fantastisch-kontrafaktische Variation der Realität anmutet, könnte letztlich auch nur die subjektive - und möglicherweise verzerrte - Wahrnehmung einer Realität sein, die gewissermaßen ganz real zur Irrealität tendiert. Anders gewendet: Es lässt sich nicht letztgültig entscheiden, ob es sich bei den vordergründig fantastischen Elementen um kontrafaktische Variationen des dokumentarischen Faktenmaterials - und damit um eine künstlerische Beigabe Rögglas - handelt, oder ob das einschlägige Faktenmaterial nicht bereits an und für sich einen Eindruck von Unheimlichkeit erzeugt. $^{982}$

Im Rahmen ihres kreativen Dokumentarismus lässt Röggla somit eine ostentativ fiktionalisierende Lesart ihres Textes mit einer faktisch-dokumentarischen Lesart desselben Textes konkurrieren: nämlich eine kontrafaktisch-fantastische mit einer lediglich metaphorisch-fantastischen. Durch diese „Verschränkung dokumentarischer mit phantastischen Verfahren "983 wird in wir schlafen nicht darauf aufmerksam gemacht, dass die gewohnten epistemischen und enzyklopädischen Rahmenfaktoren, welche für eine Unterscheidung von Realität und Fiktion - und damit auch für die Bestimmung kontrafaktischer Elemente zentral sind, im Falle von New Economy, Digitalisierung und Unternehmensmanagement nicht mehr problemlos gegeben sind: Bereits die Wahrnehmung der sogenannten Realität selbst geht hier mit einem „derealisierungsgefühl“984 einher. Um derartige Themen in der Kunst überhaupt noch zur Darstellung brin-

981 Siehe zu den Möglichkeiten der Überlagerung verschiedener Weltvergleichsverhältnisse Kapitel 5.1. Realistik, Fantastik, Kontrafaktik, Faktik.

982 Damit tendiert wir schlafen nicht zu einer Manifestation des Fantastischen im Sinne Todorovs, nämlich mit einer Betonung der „Unschlüssigkeit“ angesichts eines Ereignisses, „das den Anschein des Übernatürlichen hat.“ (Todorov: Einführung in die fantastische Literatur, S. 34).

983 Susanna Brogi / Katja Hartosch: Dokumentarische(s) Arbeiten - Arbeit dokumentarisch. In: Susanna Brogi u. a. (Hg.): Repräsentationen von Arbeit. Transdisziplinäre Analysen und künstlerische Produktionen. Bielefeld 2013, S. 449-475, hier S. 461.

984 Kathrin Röggla: geisterstädte, geisterfilme. In: Dies.: disaster awareness fair. zum katastrophischen in stadt, land und film. Wien 2006, S. 7-30, hier S. 18. 
gen zu können, bedarf es eines, wie Julia Schöll schreibt, „gespenstischen Realismus“, also eines Realismus, der epistemische Ambivalenzen, Unheimliches, fantastische und kontrafaktische Elemente integriert - nicht, um sich von der Realität $\mathrm{zu}$ entfernen, sondern um im Gegenteil deren eigene Irrealität künstlerisch kenntlich zu machen. ${ }^{985}$

\subsubsection{Unsichtbare Selbsteinschreibungen}

Ein Kurzabschnitt ganz zu Beginn von wir schlafen nicht lautet: „ob das jetzt das interview sei? ,ist das jetzt das interview‘, um das gebeten worden sei?“ (wsn, 9) Auch im weiteren Verlauf des Textes wird immer wieder angedeutet, dass die mehr oder weniger umfänglichen Monologe der Sprecher als Antworten auf die Fragen einer Interviewinstanz zu verstehen sind. Diese Instanz allerdings tritt im Text selbst nicht in Erscheinung und erhält auch keinen Namen. Man erfährt kaum mehr von ihr, als dass sie weiblich und „keine journalistin“ (wsn, 7) ist. Auch ihre Fragen werden im Text selbst nicht genannt. Allenfalls lassen sich ihre Redebeiträge aus den Antworten ihrer Gesprächspartner - gleichsam über ihren Negativabdruck im Diskurs - rekonstruieren.

Es wurde bereits erwähnt, dass dem Haupttext von wir schlafen nicht eine Vorbemerkung vorangestellt ist, in der „kathrin röggla“ ihren „gesprächspartnern“ (wsn, 4) dankt. Dieser Paratext bildet einen starken Hinweis darauf, dass die unsichtbare respektive implizite Interviewinstanz auf Kathrin Röggla selbst verweist. Auch der für Rögglas Schreiben so typische Einsatz des Konjunktivs lässt sich als Teil dieser indirekten Selbsteinschreibungsstrategie begreifen: Als grammatikalische Form der indirekten Rede deutet der Konjunktiv auf eine vermittelnde Instanz hin. Da aber überhaupt weite Teile des Textes im Konjunktiv stehen, erscheint es plausibel, die implizite Interviewinstanz mit der Erzählinstanz von wir schlafen nicht gleichzusetzen. Jene Instanz, die zum Sprechen

\footnotetext{
985 Schöll: Dead or alive, S. 107. An späterer Stelle ihres Aufsatzes bemerkt Schöll: „Ist das Unheimliche, wie schon bei Freud skizziert, die Wiederkehr des eigentlich Vertrauten, aber Verdrängten, das an die Oberfläche des Bewusstseins und somit in die Realität zurückgeholt wird, so sind Kathrin Rögglas unheimliche Textstrategien, ihre textuellen Verschleierungstaktiken und gespenstischen Kippfiguren durchaus mit dem realistischen Anspruch ihrer Texte vereinbar. Sie stehen nicht im Widerspruch zu ihrem eignen Wirklichkeitsbezug, sondern bilden dessen genuine Basis.“ (Ebd., S. 121).
} 
anregt - und deren Gleichsetzung mit „kathrin röggla“ zu Beginn des Textes nahegelegt wird -, fiele dann mit derjenigen Instanz zusammen, die das Gesprochene präsentiert, sodass letztlich beinahe der ganze Text als durch die Interviewerin vermittelt erschiene. ${ }^{986}$ Entgegen dem vordergründigen Eindruck der Abwesenheit wäre die Interviewinstanz im Text also tatsächlich omnipräsent und fungierte, wie Röggla in einem Interview bemerkt, als „vampirhafte Bauchrednerfigur“, welche „die Lebendigkeit des anderen aussaugt“. ${ }^{987}$

Die Unsicherheit hinsichtlich der Authentizität respektive der faktischen Referenzen des Erzählten wird durch diesen impliziten Verweis auf die reale Autorin jedoch keineswegs aufgehoben. Im Gegenteil: Indem sich Röggla in einen dokumentarischen Text einschreibt, der sein Material auf erkennbare Weise variiert, wird die Unsicherheit hinsichtlich der Authentizität des Recherchematerials selbst noch auf die Interviewinstanz ausgedehnt. Eva Kormann hält diesbezüglich fest:

[Die] homodiegetische Erzählinstanz nähert sich der realen Autorin an, die in der Vorbereitung ihres literarischen Projekts wir schlafen nicht Interviews geführt hat. Diese Engführung von homodiegetischem Erzählen und der Recherche der Autorin kann bei den Lesenden Irritationen hervorrufen: Sie können nicht unterschieden, ob sie eine dokumentarische Reportage oder ein fiktionales Werk, das mit einer Metalepse irritieren will, vor sich haben. ${ }^{988}$

Indem sich Röggla also in die fiktionale Welt einschreibt - wenn auch als weitgehend unsichtbare Instanz -, gerät sie selbst $\mathrm{zu}$ einer autofiktionalen und damit potenziell kontrafaktischen Figur. ${ }^{989}$ Inwiefern die implizite Interviewinstanz dabei im Einzelnen mit der empirische Person Kathrin Röggla übereinstimmt, kann anhand des Textes nicht mehr entschieden werden (so wie ja

986 Im Essay die rückkehr der körperfresser bezeichnet Röggla das „wackelige[...], ich““ als „die textstelle, durch die alles durchmuss und um die ich herumeiere seit einiger zeit, weil dieses ,ich` einem im grunde nur auf den wecker gehen kann. dieses hybride geschöpf, das andauernd ein zentrum im text suggeriert, einen essentialisierungsherd, der die dinge eher zum überkochen als zum kochen bringt. [...] das, ich“ ist nur eine stelle, ein aktualisierungsmoment des diskurses, der uns abspielt“ (Röggla: die rückkehr der körperfresser, S. 40 f.).

987 Röggla / Kaiser / Böhnke: Die gouvernementalen Strukturen, S. 176.

988 Eva Kormann: Jelineks Tochter und das Medienspiel. Zu Kathrin Rögglas wir schlafen nicht. In: Ilse Nagelschmidt / Lea Müller-Dannhausen / Sandy Feldbacher (Hg.): Zwischen Inszenierung und Botschaft. Zur Literatur deutschsprachiger Autorinnen ab Ende des 20. Jahrhunderts. Berlin 2006, S. 229-245, hier S. 232.

989 Kormann weist darauf hin, dass auch Rögglas „Werke really ground zero (2001) und tokio, rückwärtstagebuch zwischen Autobiografik und fiktionaler Literarizität schillern.“ (Korman: Wer spricht?, S. 129) Siehe zur Verbindung von Kontrafaktik und Autofiktion Kapitel 5.3. Kontrafaktische Genres. 
überhaupt etwaige Detailübereinstimmungen zwischen fiktionaler und realer Welt am Text selbst nicht überprüfbar sind). ${ }^{990}$ Die pseudo-reale Interviewinstanz in wir schlafen nicht verbürgt also gerade keine Authentizität, sondern muss vielmehr als weiteres Element jenes kreativen Dokumentarismus betrachtet werden, den der Text durchgehend praktiziert.

Die dynamische Funktion einer solchen autofiktionalen Interviewinstanz im Rahmen eines genuin literarischen Dokumentarismus fasst Röggla in ihrem Essay Stottern und Stolpern. Strategien einer literarischen Gesprächsführung folgendermaßen zusammen:

Ein literarisches Arbeiten, das klassische dokumentarische Verfahren anwendet, sollte dies thematisieren und deswegen dialogisch vorgehen. Das heißt nicht, wie ein Journalist sich erst einmal einen geschlossenen „Rechercheblock“ vorzunehmen, der gesondert von der „eigentlichen“ ästhetischen Arbeit zu sehen ist, sondern ein Hin und Her zwischen diesen Ebenen, eine Ineinanderführung. Denn das Recherchematerial ist Teil dieser Ästhetik, auch werde ich, wenn ich Gespräche mit Unternehmensberatern führe, zu fünfzig Prozent an diesen beteiligt sein, selbst wenn es nicht so aussehen mag. Mein Interesse kann nicht sein, eine vermeintliche Objektivität des Gesagten zu suggerieren und ein Fenster zur Welt zu öffnen, ich werde die Position des Fragenden hinnehmen müssen und mit dieser Position auch stellvertretend den Leser oder die Leserin. ${ }^{991}$

Tatsächlich finden sich in wir schlafen nicht immer wieder Passagen, in denen die Schwierigkeit - oder Weigerung - der Erzählinstanz, das Gehörte in authentischer Form wiederzugeben, thematisiert oder formal angedeutet wird:

„aber daß sie mich da nicht in schwierigkeiten bringen!“

„stimmt! wirkliche namen habe ich ja keine gesagt.“

„aber daß sie mir das nicht zu genau zitieren, ja?“

sie meine so eins zu eins. (wsn, 53)

Ausgerechnet der letzte Satz mit der Formulierung „eins zu eins“ steht hier im Konjunktiv und ohne Anführungszeichen. Indem die Möglichkeit des wörtlichen Zitierens im Text solcherart nur in grammatikalisch leicht variierter Form erscheint, stellt sich ein genereller Zweifel hinsichtlich der Fähigkeit oder Bereitschaft der Interviewerin ein, die Aussagen der Interviewten im gedruckten Text unverändert wiederzugeben. Diese Unfähigkeit oder Unwilligkeit zum

990 In ihrer Saarbrücker Poetikdozentur bemerkt Röggla hierzu: „Ich bin also eine Realfiktion und so was färbt natürlich auf meine Figuren ab, sorry. “ (Röggla: Die falsche Frage, S. 80).

991 Kathrin Röggla: Stottern und Stolpern. Strategien einer literarischen Gesprächsführung. In: Dies.: besser wäre: keine. Essays und Theater. Frankfurt a. M. 2013, S. 307-331, hier S. 330 f. 
wörtlichen Zitat wird an einer früheren Stelle des Textes mit noch größerer Deutlichkeit herausgestellt:

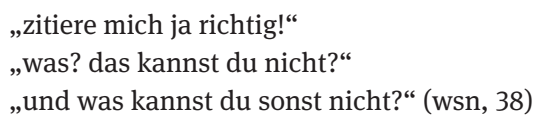

In einer paradox-humoristischen Wendung erscheint hier gerade das NichtKönnen als Skill, der im Gespräch, nebst anderen (Nicht-)Skills, abgefragt werden kann. Zugleich wird die Unfähigkeit zum korrekten Zitat - in genauer funktionaler Verkehrung der zuvor erläuterten Passage - hier textuell unterlaufen, wenn ausgerechnet die Feststellung, dass die Interviewerin nicht korrekt zitieren kann, von der Interviewerin - zumindest formal - korrekt zitiert wird, nämlich im Indikativ und in Anführungszeichen. Die Unzuverlässigkeit der Erzählinstanz wird somit anhand eines performativen Widerspruchs in eine, wenn man so will, unzuverlässige Unzulässigkeit überführt: Selbst auf die Unzuverlässigkeit der Erzählinstanz ist letztlich kein Verlass.

Zum einen bildet diese Selbstthematisierung der impliziten Interview- und Erzählinstanz einen Teilaspekt jener Produktion von Uneigentlichkeit, die oben bereits thematisiert wurde: Ein Interview, in welchem immer nur eine Person spricht, kann unmöglich ein authentisches, dem Anspruch nach also möglichst vollständiges oder zumindest nicht aktiv verfälschendes Interview sein. ${ }^{992}$ Die künstlerische Bearbeitung - respektive kontrafaktische Variation - ist hier also offenkundig. Zum anderen kommt den unsichtbaren Selbsteinschreibungen der Erzählinstanz aber auch eine spezifischere Bedeutung für das kritische Projekt von wir schlafen nicht zu. Die abwesende Interviewinstanz, die zugleich den Text in seiner Gesamtheit zu organisieren scheint, verweist nämlich in Rögglas Text auf die Funktionsweise der Unternehmensberatung selbst: Die strategischen Interessen der Welt der Unternehmensberatung, welche sich in bestimmten Sprachformen und Praktiken der Einflussnahme bei gleichzeitiger konsequenter Verschleierung der eigenen Parteilichkeit abzeichnen, korrespondieren in wir schlafen nicht mit den strategischen Interessen der Erzählinstanz. Röggla kommentiert diesen Parallelismus zwischen beschriebenem und beschreibendem Diskurs wie folgt:

992 Unvollständigkeit der Darstellung führt zwar keineswegs automatisch zu Fiktivität oder zum Zusammenbruch von Referenz. Ein Teil der, wenn man so will, Referenzkonvention der faktualen Gattung Interview besteht allerdings in der Forderung, die Fragen des Interviewers mitanzugegeben. Genau diese Konvention wird in Rögglas Text unterlaufen. 
Und dann bin ich, eigentlich über totale Umwege, auf die Unternehmensberater gekommen. [...] Ich habe gemerkt, wenn ich mit denen spreche, ist da etwas, das genau zu einer gewissen ästhetischen Struktur passt, die ich schon entwickelt hatte: einen Erzähler im Zentrum, der nicht sichtbar ist, der sich immer entzieht und scheinbar neutral ist. Und diese Unternehmensberater müssen genau das machen: Sie müssen sich scheinbar neutral halten, haben aber natürlich totales Interesse und können das immer verdecken. Dazu kam, dass das wirklich das Herz der Finsternis ist. Da werden tatsächlich Entscheidungen getroffen, die eine Wirksamkeit, also eine Realitätsmacht haben. ${ }^{993}$

Die formale Anlage von Rögglas Text sowie dessen kritische Stoßrichtung lassen sich mithin als Produkte einer formalen Wahlverwandtschaft zwischen zwei Diskursen auffassen. Indem ,Röggla‘ scheinbar aus den konkreten Interviewsituationen verschwindet, zugleich aber gerade aus dieser unsichtbaren Position heraus den Textverlauf steuert, tritt sie strukturell in die Position der Unternehmensberater ein. Ähnlich wie eine McKinsey-Beraterin sich aus der Verantwortung stehlen mag, wenn sie einem Unternehmen eine Reihe von Entlassungen zwar angeraten, diese Entlassungen aber nicht selbst durchgeführt hat (vgl. wsn, 37), so schützt auch die Erzähl- und implizite Interviewinstanz von wir schlafen nicht ein neutrales Interesse vor, wenn sie vordergründig lediglich das wiedergibt, was in den Interviews gesagt wurde. Tatsächlich praktiziert sie aber eine „hysterische Affirmation“994, treibt ihre Interviewpartner also in Formen der exzessiven diskursiven Selbstlegitimation hinein, die früher oder später unausweichlich scheitern - und damit die kompromittierenden Wahrheiten über die inhumane Arbeitsrealität der Branche offenlegen. Genau diese scheiternde Selbstlegitimation wird in wir schlafen nicht dann mittels Verfremdung, formaler Kontrafaktik und einer bestimmten Dramaturgie des Arrangements besonders sinnfällig gemacht; die kritische Stoßrichtung des Textes erwächst aus der fiktio-

993 Röggla: „Literatur ist ja nicht nur Theorie, sondern auch Erfahrung“, S. 49. Siehe hierzu auch dies.: Im Moment durchkreuze ich den Feldbegriff mit meiner Arbeit, S. 171f. Der Begriff „Herz der Finsternis“ lässt sich dabei angesichts von Rögglas poetologischen Überlegungen nicht auf ein fixes Zentrum oder einen ,eigentlichen` Kern hinter den Management-Diskursen beziehen. Vielmehr muss hier Rögglas Erwähnung der „Wirksamkeit“ des Diskurses hervorgehoben werden: So wie in Joseph Conrads Erzählung Heart of Darkness existiert auch im Falle der Management-Diskurse möglicherweise gar kein eigentliches Zentrum, auf das sich die erfahrenen Wirkungen originär zurückführen ließen; vielmehr ist es die Erfahrung der in ihrem Ursprung letztlich inkommensurablen Wirkungen, welche die Hypostasierung eines Zentrums allererst provoziert.

$994 \mathrm{Zu}$ ihrer Interviewpraxis bemerkt Röggla: „Diese Haltung könnte man als hysterische Affirmation bezeichnen, also auf eine Weise wollte ich die Gesprächspartner in ihre Rhetoriken hineintreiben, zu einer Art Essenz dieses Diskurses zu kommen [sic], d. h. sie durch Affirmation stärker in die Risse und Widersprüche des Diskurses zu treiben.“ (Röggla / Kaiser / Böhnke: Die gouvernementalen Strukturen, S. 176). 
nal-strategischen Betonung der Widersprüchlichkeiten des dokumentierten Diskurses. Hinter der vordergründigen Neutralität der Interviewinstanz verbirgt sich somit ein, wie Röggla an anderer Stelle bemerkt, „vampirismus des fiktionalen“995, ein künstlerisches Eigeninteresse also, das fremde Diskurse gerade nicht in ihrer Selbstständigkeit gelten lässt, sondern sie für künstlerisch-kritische Zwecke instrumentalisiert.

Entsprechend kann es kaum überraschen, dass auch die Interviewpartner im Fortgang des Textes ein immer größeres Misstrauen gegenüber der Interviewerin an den Tag legen: „das sind ja fragen! man fühlt sich direktgehend observiert.“ (wsn, 143) Gegen Ende von wir schlafen nicht scheint den Sprechern zusehends deutlich zu werden, dass die Interviewinstanz keineswegs eine neutrale Position einnimmt, sondern ihre ganz eigenen Interessen verfolgt:

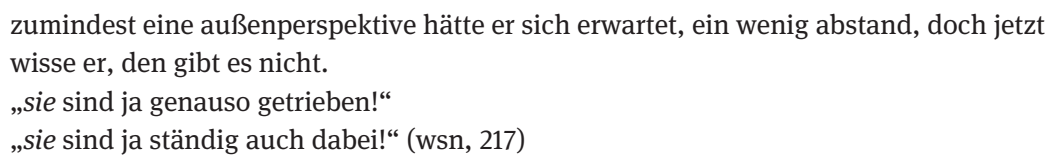

Die Unfähigkeit, eine neutrale Position außerhalb des Diskurses einzunehmen, wird hier ausgerechnet von den Unternehmensberatern moniert, deren eigenes Geschäftsmodell doch gerade auf dem Prinzip der Einmischung beruht. Dort, wo die Sprecher der Funktionsweise des eigenen Diskurses in einem fremden Bereich begegnen, wo den Unternehmensberatern also durch die Interviewerin ein Spiegel ihrer eigenen Handlungslogik vorgehalten wird, reagieren sie mit Ablehnung oder gar mit Aggression. Damit brechen sie allerdings - ohne dies selbst zu merken - zugleich den Stab über die eigene Sprech- und Handlungsweisen.

Tatsächlich fungiert die implizite Interviewinstanz in wir schlafen nicht gewissermaßen selbst als Unternehmensberaterin, insofern sich ihr Vorgehen mit demjenigen der Unternehmensberater, wenn nicht inhaltlich, so doch formal parallelisieren lässt. Auch bei der Interviewinstanz handelt es sich, wie es in der allerersten Interview-Passage des Textes heißt, um einen der „menschen, die gar nicht so sehr in erscheinung träten, zumindest zunächst, aber in wirklichkeit die fäden zögen.“ (wsn, 7) Die Funktionsweise der Unternehmensberatung schlägt somit gleichsam auf die immanente Poetik von Rögglas eigenem Text durch. „Der Erzählergeist“, so die Autorin, „war der diabolische Geist der Unternehmensberater selbst. “996 Das bedeutet aber auch, dass wir schlafen

995 Röggla: die rückkehr der körperfresser, S. 32.

996 Kathrin Röggla / Susanna Brogi / Katja Hartosch: „Manage dich selbst oder stirb.“ Die Autorin Kathrin Röggla im Gespräch. In: Susanna Brogi u. a. (Hg.): Repräsentationen von Ar- 
nicht die Funktionsweise der Unternehmensberatung nicht (nur) anhand einzelner inhaltlicher Aspekte, sondern ebenso anhand formalästhetischer Kategorien, eben dem „Erzählergeist“, kenntlich macht. Der Text behauptet somit nicht einfach, dass die Funktion der Unternehmensberatung in einem Steuerungskalkül bestehe, welches die eigenen Interessen gleichzeitig permanent zu verdecken trachtet; vielmehr macht der Text dieses Kalkül selbst ästhetisch erfahrbar, indem er die Funktionsweise einer Instanz, die aus dem Verborgenen heraus einen fremden Diskurs zu lenken sucht, textperformativ vorführt. Gerade die kontrafaktische Tilgung der Interviewinstanz erweist sich somit als Technik eines kreativen Dokumentarismus, der mit seiner eigenen formalen Anlage in Resonanz zum strategischen Kalkül des dokumentierten Diskurses tritt. Paradoxerweise fungiert somit in wir schlafen nicht ausgerechnet die Kontrafaktik, also eine künstlerische Form der Abweichung von Fakten und Dokumenten, als zentrales dokumentarisches Verfahren.

\subsubsection{Schlussbetrachtung: der kritische Text}

Künstlerische Verfremdungsverfahren und realweltliches Material stehen im Falle von Rögglas kreativem Dokumentarismus, so sollte deutlich geworden sein, in einem engen Abhängigkeitsverhältnis zueinander. Die Themen dieses Dokumentarismus - im Falle von wir schlafen nicht also die New Economy und insbesondere die Unternehmensberatung - sind bereits an und für sich durch ein hohes Maß an Virtualität, Diskursivität und Narrativität charakterisiert: Bei der Beratung handelt es sich, wie Adrian Steiner schreibt, um ,eine ,operative Fiktion“ unter zunehmend komplexeren gesellschaftlichen Verhältnissen“, wobei zu berücksichtigen ist, „dass diese Beratung als Fiktion real ist und strukturelle Auswirkungen hat“. ${ }^{997}$ Dieser effektiven Virtualität der behandelten Diskurse begegnet Röggla mit einer Hybridisierung der literarischen Form. In ihrem Essay geisterstädte, geisterfilme schreibt sie: „nur die wahrnehmung der spannung, der umgang mit dem hybriden und vermischten wird uns $\mathrm{zu}$ der wirklichkeit führen, in der auch wir enthalten sind." "998 Um eine sich zusehends entziehende Wirklichkeit ästhetisch erfahrbar zu machen, versucht Röggla, ein Resonanzverhältnis herzustellen zwischen den Hybridisierungstendenzen der Gegenwart und der ästhetischen

beit. Transdisziplinäre Analysen und künstlerische Produktionen. Bielefeld 2013, S. 491-501, hier S. 491.

997 Adrian Steiner: Rat und Beratung. Eine kleine Begriffsgeschichte. In: Navigationen 4, 1/2 (2004), S. 155-168, hier S. 168.

998 Röggla: geisterstädte, geisterfilme, S. 30. 
Anlage ihrer Texte. Das Attribut ,realistisch` kommt Rögglas Dokumentarismus insofern nicht mehr im Sinne einer möglichst getreuen Realitätsabbildung zu, sondern vielmehr im Hinblick auf das realitätsanaloge Fiktion(alisierung)skalkül ihrer literarischen Arbeiten. Im Werk Rögglas sind es die künstlerischen Verfahren selbst - mit ihren Verfremdungen, ihren strategischen Textarrangements und ihren kontrafaktischen Materialvariationen -, die eine Art formaler Mimesis an den dokumentierten Realitätsbereich vollziehen.

„Das unternehmerische Selbst“, so schreibt Ulrich Bröckling und so zitiert ihn Röggla wörtlich in ihrer Saarbrücker Poetikdozentur, ,existiert nur als Realfiktion im Modus des Als-ob - als kontrafaktische Unterstellung mit normativem Anspruch, als Adressierung, als Fluchtpunkt von Selbst- und Sozialtechnologien, als Kraftfeld, als Sog. “999 Ein Element strategischer Fiktion ist insofern für die von Rögglas Dokumentarismus dargestellte Realität ebenso konstitutiv wie für diesen Dokumentarismus selbst; gerade die strukturelle Verwandtschaft leistet der Bearbeitung ebenjener Realität im Medium der Literatur besonderen Vorschub. Die Effekte dieser beiden Formen der ,Erfindung' sind freilich sehr verschieden: Während die Fiktionen der Realität Teilaspekte der neoliberalen und gouvernementalen Strategien der Gegenwart bilden, fungieren Rögglas ästhetische Fiktionalisierungsverfahren als Instrumente einer ästhetisch-politischen Intervention. ${ }^{1000}$ In den Brechungen von Rögglas ,neuem Realismus “ wird die Gebrochenheit der Realität selbst erkennbar; das Fiktive der fiktionalen Literatur wird in Parallele und gleichzeitig in produktive Spannung gebracht zum Fingierten der realen Welt. ${ }^{1001}$

Eine kritische Stoßrichtung lässt sich Rögglas Text dabei nicht auf der Ebene auktorialer oder figuraler Aussagen zuschreiben: In wir schlafen nicht gibt es

999 Bröckling: Das unternehmerische Selbst, S. 283; Röggla: Die falsche Frage, S. 79 f. Der hier gebrauchte Begriff des Kontrafaktischen - im schlichten Sinne der Nicht-Existenz - ist freilich nicht mit dem Begriff der Kontrafaktik identisch, wie er in der vorliegenden Studie verwendet wird. Siehe Kapitel 2.1. Terminologie.

1000 Im Interview weist Röggla darauf hin, dass in Theater und Kunst mittlerweile zwar durchaus auch Ideen von Effizienz, Flexibilität und Dynamisierung um sich griffen, wie sie für die New Economy charakteristisch sind; der prägende Einfluss gehe hier aber letztlich von der Unternehmensberatung und dem Management aus, während sich die Kunst eher reaktiv verhalte. „[I]ch hatte immer ein Unbehagen, wenn es hieß, dass die Künstler diejenigen seien, die das zuerst benutzt haben, als hätten sie das Übel in die Welt gebracht bzw. wäre es noch dasselbe. Es hängt doch immer vom Kontext ab.“ (Röggla / Kaiser / Böhnke: Die gouvernementalen Strukturen, S. 172f.).

1001 In das stottern des realismus schreibt Röggla: „,wenn ich einen text über realismus schreiben würde, käme das gerücht darin vor, der virus und die desinformation, das fingierte, das eine gegenform zum fiktiven ist“ (Röggla: das stottern des realismus, S. 24). 
keine Erzählinstanz oder privilegierte Reflektorfigur, welche die Welt der Unternehmensberatung kritisch bewerten würde. ${ }^{1002}$ Vielmehr ist es hier der Text selbst in seiner ästhetischen Organisation, der als kritische Instanz fungiert. Zurecht betont Iuditha Balint: „Rögglas Figuren erweisen sich [...] dem Neoliberalismus gegenüber recht unkritisch. Hier, in Rögglas Roman, ist es der Text als Ganzes, das fiktionale, literarische Werk, das Kritik ausübt und die struktur- und systemerhaltende Funktion seiner Figuren zum Vorschein bringt. “1003 Kritisch zur eigenen Gegenwart verhält sich Rögglas Literatur anhand formaler Verfremdungsverfahren, welche erkennen lassen, dass die Realität selbst gar nicht als ,real' in einem evidenten Sinne aufgefasst werden kann, sondern vielmehr einem bestimmten strategischen und zugleich permanent verschleierten Fiktionskalkül folgt. „Die schärfste Ideologie“ so könnte man mit Alexander Kluge formulieren, besteht darin, „daß die Realität sich auf ihren realistischen Charakter beruft.“1004

Die Illusion einer, wenn man so will, realistischen Realität bricht Röggla in wir schlafen nicht durch eine Vielzahl ästhetischer Formungsverfahren auf: Das Interviewmaterial wird auf eine begrenzte Zahl weitgehend anonymer Sprecher verteilt, „bearbeitet, verfremdet und collagiert“1005; die Interviewaussagen werden in eine dramaturgische Kurve gebracht, sodass bestimmte Aspekte der inhumanen Arbeitsrealität immer deutlicher hervortreten, etwa die konsequente Austrocknung des Privatlebens, der Einfluss von Herkunft, Beziehungen und Geschlecht auf die Karriere und nicht zuletzt die Notwendigkeit einer permanenten Verweigerung gegenüber körperlichen Grundbedürfnissen zugunsten von Arbeitsleistung und Arbeitsperformance - eine Verweigerung, die in komprimierter Form bereits im Titel des Romans zum Ausdruck kommt. Der vermittelte Status des Interviewmaterials wird sowohl durch weitausgreifende Verwendungen des Konjunktivs als auch durch eine unsichtbar-autofiktionale Selbsteinschreibung der Interviewinstanz ,Röggla‘ in den Text betont. Und nicht zuletzt greift

1002 Tatsächlich wird die Option eigener politischer Positionierung im Text sogar aktiv zurückgewiesen, wenn der Partner bemerkt: „er halte sich nun mal nicht für so einen politischen menschen, da sei nichts zu machen, er steigere sich in dererlei [sic] fragen nicht mehr rein, dafür habe er seine mitarbeiter. (lacht)“ (wsn, 103).

1003 Balint: Die Frage literarhistorischer Genrezuordnungen, S. 29. In ähnlicher Weise konstatiert Vedder: „es ist die sprachavancierte Romantechnik, die erkennbar kritisch agiert.“ (Vedder: Arbeitswelten und Ökonomie, S. 67).

1004 Alexander Kluge: Gelegenheitsarbeit einer Sklavin. Zur realistischen Methode. Frankfurt a. M. 1975, S. 215. In ihren poetologischen Äußerungen hat sich Röggla immer wieder zu dem prägenden Einfluss Kluges auf ihr eigenes Werk bekannt.

1005 Kyra Palberg: „short sleeping, quick eating“. Produktivität und Sprechen bei Kathrin Röggla. In: Iuditha Balint / Tanja Nusser / Rolf Parr (Hg.): Kathrin Röggla. München 2017, S. 278-297, hier S. 278. 
Röggla auf Motive aus dem Bereich des Gespenstischen, des Unheimlichen und der Fantastik zurück, wobei stellenweise unklar bleibt, ob nun tatsächlich ein Einbruch des Fantastischen in die fiktionale Welt stattfindet oder lediglich die Sprecher den Überblick über ihre eigene Arbeitswelt und Branchenrealität verlieren.

Anhand der genannten Verfremdungsverfahren wird in wir schlafen nicht eine künstlerische Bearbeitung des Interviewmaterials deutlich angezeigt; die Form der Präsentation schließt also die Option eines faktischen Dokumentarismus zuverlässig aus. Unklar bleibt demgegenüber, in welchem genauen Ausmaß hier eine Variation konkreten Faktenmaterials, wie es für die Kontrafaktik charakteristisch ist, stattgefunden hat. Die vorwiegend formale Kontrafaktik des Textes zeigt zwar an, dass das Interviewmaterial bearbeitet wurde; eine kohärente fiktionale Welt jedoch, welche dann in einzelnen ihrer Aspekte mit Fakten der realen Welt kontrastiert werden könnte, lässt Rögglas Text nicht entstehen. Allerdings sind derartige eindeutige Fakten - und genau auf diese Erkenntnis hebt Rögglas Dokumentarismus ab - auch in der Realität selbst nicht problemlos zu haben. Bei Unternehmensberatung, New Economy, Katastrophenberichterstattung und den weiteren Themen von Rögglas kreativem Dokumentarismus handelt es sich um Phänomene, denen man, wie die Autorin schreibt, „mit ästhetischer Linearität, Eindeutigkeitsnarrationen nicht beikommen kann. “" ${ }^{1006}$ Entsprechend erlaubt auch wir schlafen nicht keine Festlegung auf nur einen bestimmten Darstellungsmodus, sondern hält vielmehr alle vier möglichen Weltvergleichsverhältnisse - Realistik, Faktik, Kontrafaktik und Fantastik - in der Schwebe. Anders als klassische Dokumentarismen strebt Rögglas kreativer Dokumentarismus nicht mehr eine Verbreitung konkreter Einzelinformationen oder die Aufklärung der Leser an; vielmehr macht er den realitätsentrückten, gleichsam ,real-kontrafaktischen' Status der Wirklichkeit ästhetisch erfahrbar, indem er klaren Oppositionen, wie sie für die Kontrafaktik, aber auch für die Faktik des klassischen Dokumentarismus grundlegend sind, mittels vielfältiger künstlerischer Verfremdungsverfahren das Fundament entzieht. Der ,realistische‘ Charakter von Rögglas kreativem Dokumentarismus ergibt sich somit paradoxerweise gerade aus dem beständigen Ausfransen realistischer, faktischer oder dokumentarischer Erzählverfahren in Richtung unzuverlässigen, fantastischen oder kontrafaktischen Erzählens.

Diese Unsicherheiten in Bezug auf das angewandte Erzählverfahren sowie die zugrunde gelegte Realitätskonzeption machen Rögglas kreativen Dokumentarismus zu einem theoretisch produktiven Grenzfall der Kontrafaktik. Einerseits geht Röggla von einer Trennbarkeit zwischen literarischer Fiktion und Realität sowie von einer Differenzierbarkeit von Fakt und Faktenverzerrung

1006 Röggla: Essenpoetik, S. 57. 
aus, sodass eine kontrafaktische Abweichung vom Faktenmaterial in der Literatur prinzipiell möglich wäre. Tatsächlich wird eine solche kontrafaktische Faktenvariation in Rögglas Werk auch immer wieder angedeutet, sowohl durch formale Verfremdungstechniken als auch durch ein Kokettieren mit kontrafaktisch-fantastischen Erzählverfahren. Andererseits ist das Recherchematerial, das Rögglas kreativem Dokumentarismus zugrunde liegt, gar nicht in unbearbeiteter Form zugänglich, sodass der genaue Grad der Faktenabweichung innerhalb der fiktionalen Werke unbestimmbar bleibt. Auch handelt es sich beim Jargon der Unternehmensberatung bereits an und für sich um einen Diskurs, in welchem Realitätsbeschreibung und Realitätsmanipulation eine letztlich unentwirrbare Verbindung eingehen. Die für die Kontrafaktik konstitutive dialektische Abstoßungsbewegung („So ist es nicht“, „Das ist nicht wahr") wird somit in Rögglas Texten zwar immer wieder angedeutet; ob diese Bewegung jedoch im Einzelfall tatsächlich vollzogen wird, lässt sich nicht entscheiden. Entsprechend hat man es hier mit einer sehr speziellen Form der Kontrafaktik zu tun: Die Kontrafaktik steht in Rögglas Texten stets als Deutungsoption im Raum, gelangt aber nie zu einer unzweifelhaften Realisation. Interpretatorische Produktivität gewinnt die Kontrafaktik in Rögglas kreativem Dokumentarismus - konsequent paradox - just aus dieser Verweigerung ihrer unzweifelhaften Verwendung.

Einen aufschlussreichen Probefall für das Konzept der Kontrafaktik bildet Rögglas Werk nicht zuletzt im Hinblick auf die Kategorie der formalen Kontrafaktik. Akzeptiert man nämlich, dass Faktenabweichungen nicht nur propositional-inhaltlicher, sondern auch formaler oder sinnlicher Natur sein können, so rücken notwendigerweise auch die medial-formalen Bedingungen unterschiedlicher künstlerischer Darstellungsformen in den Fokus. Man kann dann die Fragen stellen, wie die referentiellen Eigenschaften unterschiedlicher Medien - und damit auch die Möglichkeiten ihres (variierenden) Bezugs auf Weltwissen - miteinander in Verbindung stehen oder auch in Spannung zueinander treten, welchen Einfluss bestimmte mediale Präsentationsformen auf die Möglichkeiten einer Darstellung von Wirklichkeit haben und auf welche Weise Faktenmaterial im Einzelfall inhaltlich und/oder formal variiert wird. Die künstlerischen Arbeiten Rögglas bieten sich als Ausgangspunkt für eine solche medienbewusste Reflexion der Kontrafaktik in besonderer Weise an, oszilliert Rögglas Werk doch häufig zwischen verschiedenen Medien und macht sich eine Kombination unterschiedlicher medialer Codes zunutze: beispielsweise in dem autofiktionalen Text tokio, rückwärtstagebuch, welcher in Kooperation mit dem Bildkünstler Oliver Grajewski verfasst wurde, oder in Rögglas Mehrfachbearbeitungen derselben Stoffe in unterschiedlichen medialen Formaten wie Prosatexten, Hörspielen und Theaterstücken. Von der Kategorie der formalen Kontrafaktik ausgehend eröffnen 
sich - freilich auch über Rögglas Werk hinaus - vielfältige Anschlussmöglichkeiten der bisherigen Kontrafaktik-Forschung an besonders medienbewusste Bereiche der Kunst- und Kulturwissenschaften: etwa an die Intermedialitätsforschung und Semiotik, die Comicforschung oder die Film- und Theaterwissenschaften.

\subsection{Ausblick: Kathrin Röggla: die alarmbereiten}

Abschließend soll ein kurzer Ausblick auf eine weitere dokumentarische Arbeit von Kathrin Röggla geboten werden: auf den Text wilde jagd aus dem Band die alarmbereiten von 2010. Trotz gewisser formaler Parallelen mit wir schlafen nicht ist das dokumentarische Verfahren hier etwas anders gelagert. Eine knappe Interpretation des Textes sowie ein Vergleich mit wir schlafen nicht kann entsprechend dazu beitragen, die formale Bandbreite von Rögglas kreativem Dokumentarismus anzudeuten.

Anders als in wir schlafen nicht gibt es in die alarmbereiten keinen Hinweis auf Interviews oder individuelle Recherchen, welche die Autorin für die Arbeit an ihrem Text durchgeführt hätte. Allerdings scheinen derartige Recherchen im Falle der hier verhandelten Themen auch gar nicht nötig, ist doch das für die alarmbereiten einschlägige Faktenmaterial ohnehin problemlos greifbar: Der Band verhandelt in sieben voneinander unabhängigen Texten die Risikodiskurse der Gegenwart, die Erregungsdynamiken der populären Medien sowie den zeitgenössischen Katastrophenvoyeurismus. Berichtet wird etwa von den Sitzungen einer Katastrophentourismus-Agentur, der Überbesorgnis sogenannter ,Helikoptereltern“ oder den Diskursen rund um die Finanzkrise. Im Zentrum stehen dabei niemals die realen Katastrophen, sondern die medialen Hysterien der Gegenwart, die Narrative des Ausnahmenzustands und das öffentliche Interesse am Risiko. ${ }^{1007}$ Die titelgebenden ,alarmbereiten' sind dabei diejenigen Subjekte, welche den zeitgenössischen Risikodiskurs permanent am Laufen halten, ohne dabei jedoch jemals zu konkreten Gefahrenquellen, unzweifelhaften Ereignissen oder den Schicksalen realer Opfer durchzudringen. ${ }^{1008}$ „Die Alarmbe-

1007 Vgl. Sonja Lewandowski: Wi(e)der eine Grammatik der Ausnahme. Kathrin Rögglas die alarmbereiten. In: Iuditha Balint / Tanja Nusser / Rolf Parr (Hg.): Kathrin Röggla. München 2017, S. 54-76, hier S. 55.

1008 Niklas Luhmann zufolge bezeichnet ,Gefahr‘ eine objektive Bedrohung, während ,Risiko“ eher eine reflexive Kategorie darstellt, die sich auf einen individuellen Wahrnehmungsprozess bezieht: „Der Unterscheidung von Risiko und Gefahr liegt ein Attributionsvorgang zugrunde, sie hängt also davon ab, von wem und wie etwaige Schäden zugerechnet werden. Im Falle von Selbstzurechnung handelt es sich um Risiken, im Falle von Fremdzurechnungen um Gefah- 
reitschaft“, so schreibt Irmtraud Hnilica, „besteht ganz offenbar unabhängig von ihrem Anlass." ${ }^{1009}$ Alarmbereit zu sein, in Katastrophenerwartung zu leben, mit Risiken zu kalkulieren - all dies sind, so suggerieren es die Texte von die alarmbereiten, weitgehend situationsunabhängige Gestimmtheiten des gegenwärtigen Zeitgeists. ${ }^{1010}$ In einer Welt, die zur Derealisierung tendiert, bietet die Erwartung der Katastrophe das Versprechen einer Rückkehr zur realen Erfahrung. So schreibt Röggla in dem Essay die rückkehr der körperfresser über den „schrecken einer katastrophe“: „plötzlich kann man sich einweben in die große geschichte [...] man ist enthalten in der situation, die so fantastisch real ist, ganz im gegensatz zu der quälenden unwirklichkeit unseres alltagslebens.“"1011

Der fünfzig Seiten umfassende Text mit dem Titel wilde jagd, der sechste innerhalb des Bandes, bildet den einzigen Text in die alarmbereiten, der auf ein konkretes realweltliches Medienereignis Bezug nimmt, nämlich auf die Entführung und Befreiung von Natascha Kampusch: Am 2. März 1998 wurde die damals zehnjährige Österreicherin auf dem Schulweg von dem arbeitslosen Nachrichtentechniker Wolfgang Přiklopil entführt. Přiklopil hielt sein Opfer danach mehr als acht Jahre lang gefangen, ehe Kampusch am 23. August 2006 die Flucht ge-

ren.“ (Niklas Luhmann: Risiko und Gefahr. In: Ders.: Soziologische Aufklärung 5. Konstruktivistische Perspektiven. Opladen 1990, S. 131-169, hier S. 148) Siehe hierzu auch Christian Sieg: Latenzzeit und Diskursgewitter. Die Abwesenheit der Katastrophe und die Präsenz des Risikos in Kathrin Rögglas die alarmbereiten. In: Iuditha Balint / Tanja Nusser / Rolf Parr (Hg.): Kathrin Röggla. München 2017, S. 236-255, hier S. 243-245.

1009 Irmtraud Hnilica: „im berühmten eigenen ton“. Kathrin Rögglas und Elfriede Jelineks Bearbeitungen der Kampusch-Entführung. In: Iuditha Balint / Tanja Nusser / Rolf Parr (Hg.): Kathrin Röggla. München 2017, S. 41-53, hier S. 46.

1010 Die These, das frühe 21. Jahrhundert sei durch eine gesteigerte Katastrophenerwartung charakterisiert, wurde in der kulturwissenschaftlichen Diskussion der letzten Jahre verschiedentlich ventiliert. So bemerken etwa die Herausgeber des Bandes Tickle your Catastrophe! mit Blick auf die Stimmung zu Beginn des 21. Jahrhunderts: „We have moved from the 'present past' of trauma to the 'present future' of catastrophe." (Frederik Le Roy u. a.: Introduction. In: Dies. (Hg.): Tickle your Catastrophe! Imagining Catastrophe in Art, Architecture and Philosophy. Gent 2011, S. 1-9, hier S. 1) Auch Hans Ulrich Gumbrecht konstatiert, dass „unsere Zukunft keineswegs mehr als ein offener Horizont von Möglichkeiten erlebt [wird], sondern als eine Reihe von Bedrohungen, die auf uns zukommen.“ (Hans Ulrich Gumbrecht: Zentrifugale Pragmatik und ambivalente Ontologie: Dimensionen von Latenz. In: Ders. / Florian Klinger (Hg.): Latenz. Blinde Passagiere in den Geisteswissenschaften. Göttingen 2011, S. 9-19, hier S. 18).

1011 Röggla: die rückkehr der körperfresser, S. 35. 
lang. ${ }^{1012}$ Der Fall zog enorme öffentliche Aufmerksamkeit auf sich, sodass Kampusch zeitweise zu einem Star in der Medienlandschaft wurde. ${ }^{1013}$

Rögglas Text wilde jagd verhandelt nicht den Fall Kampusch an sich, sondern die persönlichen und medialen Diskurse, die durch diesen Fall in Gang gesetzt wurden. So wie in wir schlafen nicht die eigentlichen Arbeitsabläufe, die realen Wirtschaftsstrukturen und selbst die Menschen, die auf einer niedrigeren Ebene von den Entscheidungen des Managements betroffen sind, nicht direkt zur Darstellung gelangen, so werden auch in wilde jagd der eigentliche Tathergang sowie die Perspektive des Opfers überlagert und verdeckt von medialen ,Peridiskursen‘: jenen Diskursen also, die sich um das tatsächliche Ereignis herumgruppieren. ${ }^{1014}$ Der Fokus von Rögglas Text liegt somit weniger auf dem Fall Kampusch selbst, sondern auf den Subjektpositionen, welche ein Fall wie die Kampusch-Entführung für andere Personen - Hobbypsychologen, Journalismus-Aspiranten, sich mit dem Opfer identifizierende Teenager etc. - eröffnet.

Der hochgradig vermittelte Zugriff auf das Ereignis wird in wilde jagd bereits vor Beginn des eigentlichen Textes bildkünstlerisch angedeutet: Eine comicartige Zeichnung von Oliver Grajewski, zu sehen in Abbildung 5, zeigt

1012 Der Begriff ,Opfer‘ wird hier und im Folgenden in einem nicht-wertenden Sinne gebraucht; es soll damit keineswegs die agency - also die Fähigkeit zur eigenständigen Handlung - der realen Person Natascha Kampusch in Frage gestellt werden. In ihrer Autobiografie bezeichnet Kampusch selbst sich als ,Opfer‘ und Přiklopil als ,den Täter‘. Vgl. Natascha Kampusch mit Heike Gronemeier und Corinna Milborn: 3096 Tage. Berlin 2010.

1013 Kathrin Röggla hat sich als erste prominente Autorin mit dem Fall Kampusch und dessen medialer Verarbeitung auseinandergesetzt, nämlich in dem Stück Die Beteiligten (2009) sowie in dem Prosatext wilde jagd (2010). Im Jahre 2011 nahm Elfriede Jelinek in ihrem Stück Winterreise auf den Fall Bezug. Im Jahre 2013 kam der Spielfilm 3096 Tage von Sherry Hormann, die Verfilmung von Kampuschs gleichnamiger Autobiografie aus dem Jahre 2010, in die Kinos. Siehe aus der Forschung Irmtraud Hnilica: „im berühmten eigenen ton“; dies.: 3096 Tage Arbeit. Elfriede Jelinek, Natascha Kapusch, Sherry Hormann. In: Iuditha Balint u. a. (Hg.): Opus und labor. Arbeit in autobiographischen und biographischen Erzählungen. Essen 2018, S. 231-246; Andrea Bartl: „Natascha“. Zur Literarisierung des österreichischen Kriminalfalls Kampusch. Ein Werkstattbericht. In: Friedhelm Marx / Julia Schöll (Hg.): Literatur im Ausnahmezustand. Beiträge zum Werk Kathrin Rögglas. Würzburg 2019, S. 217-233.

1014 Sowohl in wir schlafen nicht als auch in die alarmbereiten vermeidet Röggla konsequent die Ausgestaltung von Opferperspektiven. Röggla hat verschiedentlich auf die Gefahr hingewiesen, bei der künstlerischen Darstellung gesellschaftlich benachteiligter Personen Sozialvoyeurismus zu betreiben: „Ich spreche seltener mit den sogenannten Opfern der Gesellschaft, habe höchsten Respekt vor der Gefahr in Sozialvoyeurismus zu verfallen, eine sekundäre Viktimisierung zu betreiben.“ (Röggla: Essenpoetik, S. 31) In Bezug auf Rögglas literarische Verhandlung des Falles Kampusch hält Andrea Bartl fest: „Rögglas Texte wahren respektvoll die Diskretion der realen Person gegenüber und verweigern sich damit, selbst in die Voyeurismusund mediale Missbrauchsfalle zu tappen.“ (Bartl: „Natascha“, S. 229, Anm. 29). 

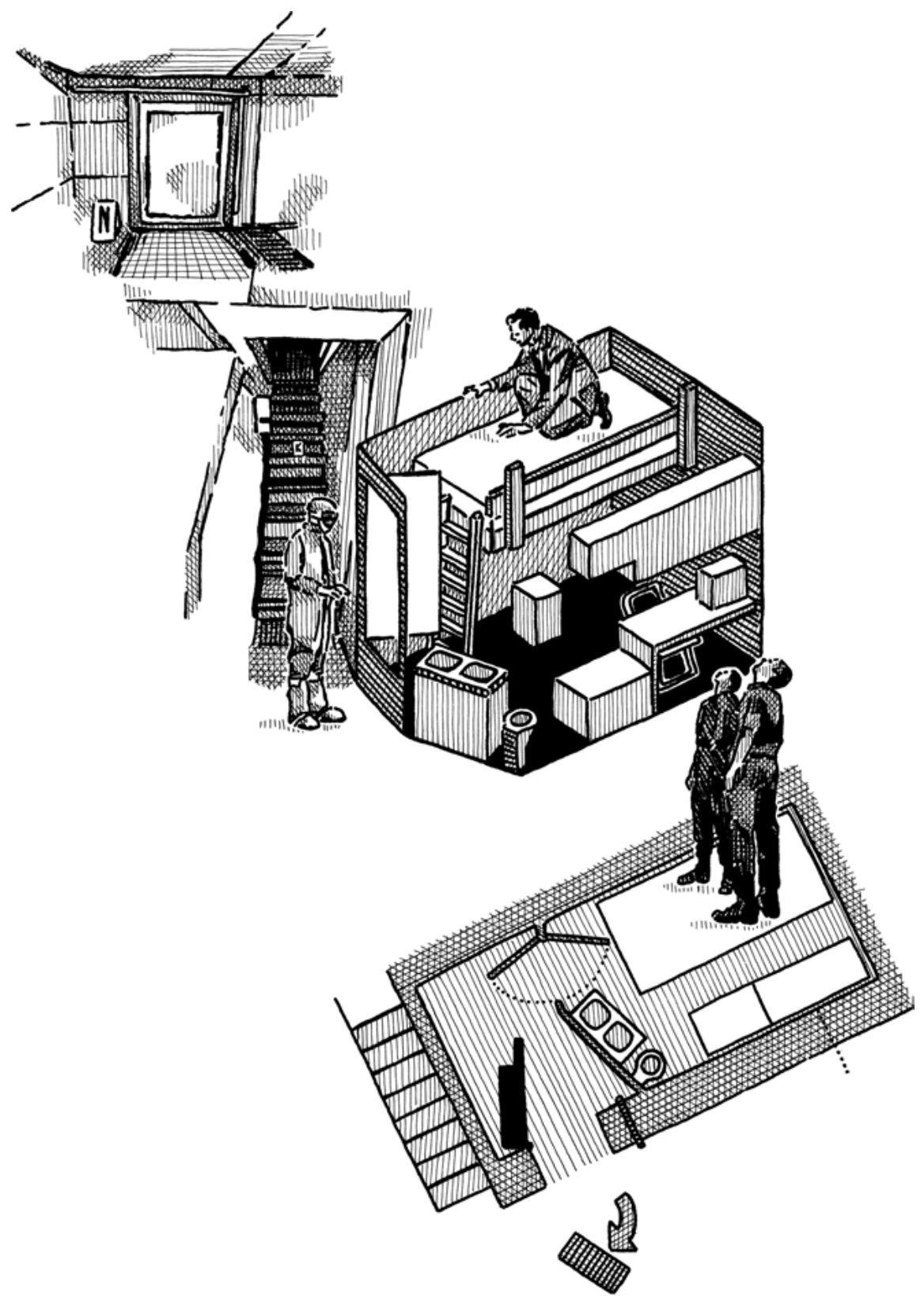

Abbildung 5: Zeichnung von Oliver Grajewski in Kathrin Rögglas die alarmbereiten, S. $120{ }^{1015}$

1015 Für die Bereitstellung der Zeichnung danke ich Oliver Grajewski. 
eine Tür ohne Klinke, ein kleines Zimmer mit einem Tisch, Schränken, Waschbecken, Toilette und einem Hochbett sowie den Lageplan des Zimmers. Zu sehen sind ferner vier Personen - eine davon in Maske und Schutzanzug -, die offenbar Untersuchungen oder Messungen im Zimmer vornehmen. Zwei der Personen, die durch Schraffur und Schattenwurf als dreidimensionale Körper erscheinen, stehen auf dem zweidimensionalen Zimmerplan, sodass sich eine Art paradoxe Überlagerung zweier perspektivischer Darstellungsoptionen ergibt.

Ähnlich wie die Coverabbildung von wir schlafen nicht verweist auch diese Zeichnung bereits auf zentrale Verfahren und thematische Schwerpunkte von Rögglas Text: Für diejenigen Betrachter, die mit den Details des Falles Natascha Kampusch vertraut sind, etabliert die Zeichnung einen deutlichen Bezug auf das Verließ unter der Garage des Entführers Přiklopil, in welchem Kampusch jahrelang gefangen gehalten wurde. Zugleich deutet die formale Verfremdung der Darstellung darauf hin, dass der Gegenstand dieser Darstellung nur indirekt zugänglich ist, unter anderem nämlich über die Vermittlung der gezeichneten Experten. Diese Experten allerdings sind - darauf deuten die suchend-spähenden Gesten und Körperhaltungen im Bild hin - ebenfalls auf Rekonstruktionen und Spekulationen angewiesen. ${ }^{1016}$ Die tatsächlichen Vorgänge der Entführung hingegen entziehen sich der Wahrnehmung: Weder das Opfer der Entführung noch der Entführer sind im Bild zu sehen.

Der eigentliche Text von wilde jagd beginnt mit der folgenden Vorbemerkung:

man erinnert sich nicht? ein jeder wird sich daran erinnern, schließlich waren wir alle dabei, wir alle haben noch gut vor augen: dieses foto von diesem mädchen im gras und der decke darüber. die polizistin, der polizist daneben, die haustür dahinter und „spektakuläre selbstbefreiung nach 8 jahren höhlendasein“ die bildunterschrift. auf der anderen seite der kamera die journalisten, das heranrasende betreuungsteam: psychologe, sozial-arbeiter, öffentlichkeitsarbeiter, medienmensch, jurist. und einen moment danach kommen sie schon: der quasifreund, der möchtegern-journalist, die pseudo-psychologin, die irgendwie-nachbarin, die optimale 14jährige, das verschenkte nachwuchstalent, kurz, die wilde jagd. ${ }^{1017}$

$(\mathrm{ab}, 121)$

Mit dem Verweis auf die Erinnerung und dem Nachdruck auf den Umstand, dass „wir alle dabei [waren]“, wird hier explizit ein bestimmtes Faktenwissen der Leserschaft vorausgesetzt. Tatsächlich dürften die Rede vom ,Mädchen unter der Decke“ und insbesondere die Schlagzeile „spektakuläre selbstbefrei-

1016 Hnilica bemerkt hierzu: „Bereits diese Illustration löst beim Betrachter nicht nur die Zuordnung des Textes zum Entführungsfall Natascha Kampusch aus, sondern deutet an, dass die mediale Berichterstattung über den Entführungsfall zu einer allgemeinen Pseudo-Expertise geführt hat.“ (Hnilica: „im berühmten eigenen ton“, S. 47).

1017 Zitate aus die alarmbereiten werden nach folgender Ausgabe mit der Sigle ,ab“ im Text gegeben: Kathrin Röggla: die alarmbereiten. Frankfurt a. M. 2012. 
ung nach 8 jahren höhlendasein“ bei den meisten Lesern die Erinnerung an die Entführung und Befreiung Natascha Kampuschs wachrufen. Durch den Hinweis auf das ,foto“ sowie durch die Anführungszeichen, welche die Schlagzeile rahmen, wird hier allerdings zugleich die mediale Vermitteltheit der aufgerufenen ,Erinnerungen“ exponiert: Die Reminiszenzen an den Fall Natascha Kampusch der Name selbst wird im Text nirgends genannt - beziehen sich weniger auf die realen Ereignisse, sondern auf die mediale Berichterstattung darüber. Ferner macht der Text darauf aufmerksam, dass ein Fall wie derjenigen Kampuschs eine ganze Reihe von Personen auf den Plan ruft, die ihren Subjektstatus in der (Medien-)Gesellschaft just ihrem Involvement in derartige Fälle verdanken: von professionell agierenden Personen wie Psychologen und Sozialarbeitern bis hin $\mathrm{zu}$ eher fragwürdigen Akteuren wie dem „quasifreund, de[m] möchtegernjournalist[en],“ oder „d[er] pseudo-psychologin“.

In wilde jagd gibt es, ebenso wie in wir schlafen nicht, keine extradiegetische Erzählinstanz. Der Text besteht aus Sprecherpassagen, die einzelnen namenlosen Figuren wie dem „quasifreund“ oder der „pseudo-psychologin“ zugeordnet sind (womit wiederum eine Gattungshybridisierung aus Prosa- und Dramentext vorgenommen wird; tatsächlich hat Röggla den Stoff von wilde jagd erstmals in einer Theaterfassung mit dem Titel Die Beteiligten (2009) bearbeitet. ${ }^{1018}$ ). Rudimente einer Handlung lassen sich dabei allenfalls aus vereinzelten szenischen Beschreibungen wie der folgenden erschließen: „der quasifreund: aber wo wolle ich denn hin, warum stürzte ich jetzt so plötzlich in dieses kaufhaus hinein? [...] er komme ja gar nicht nach.“ (ab, 127) Auch der Text von wilde jagd steht weitgehend im Konjunktiv; anders als in wir schlafen nicht wird allerdings nicht die dritte Person Singular oder Plural verwendet, sondern die erste Person Singular. Dieses „ich“ verweist dabei nicht auf die jeweiligen Sprecher, sondern auf ,Kampusch“ selbst. ${ }^{1019}$ (Im Folgenden wird als Sprecherin des Textes ,Kampusch“ in einfache Anführungszeichen gesetzt, um die Künstlichkeit dieser Sprechinstanz bei

1018 Dem Band die alarmbereiten liegt ein Hörspiel desselben Titels zugrunde, das im Jahre 2009 vom Bayerischen Rundfunk ausgestrahlt wurde. In der Hörspiel-Fassung von die alarmbereiten wird der Fall Kampusch allerdings noch nicht behandelt.

1019 Zur Sprechsituation in die alarmbereiten hält Anna Rutka fest: „Das Verschieben der sprachlichen Darstellung ins Indirekte evoziert den Eindruck, dass die Leser es mit keiner authentischen Rede und mit keinem individuellen Handeln zu tun haben. Wohl gemerkt, weder den Betroffenen noch denen, die über sie sprechen, wird im Text Autonomie eingeräumt. Der Konjunktiv und die Verdoppelung der Sprachsituationen ermöglichen es, die medial und institutionell gesteuerten Diskurse und sozialen Dispositive offenzulegen. “(Anna Rutka: Zeitgenössische Gesellschaft und ihre Ängste. Zur sprachlichen Re-Inszenierung des Katastrophischen in Kathrin Rögglas Prosaband die alarmbereiten. In: Iwona Bartoszewicz / Marek Hałub / Tomasz Małyszek (Hg.): Kategorien und Konzepte. Wrocław 2014, S. 99-112, hier S. 101f.). 
gleichzeitiger deutlicher Referenz auf die realweltliche Person Natascha Kampusch anzudeuten). ,Kampusch“ wird somit zum Sprachrohr all jener Personen, die sich um sie und ihren Fall herum positionieren. Ihre eigenen Meinungen, Wahrnehmungen und Empfindungen bringt sie hingegen nicht zum Ausdruck. Tatsächlich wird immer wieder ihr „schweigen“ betont, etwa in performativ widersprüchlichen Passagen wie: ,sie sei ja angewiesen auf das, was aus den medien komme, d. h., was andere über mich sagten, denn ich selbst sagte nichts.“ (ab, 140) Trotz gewisser formaler Ähnlichkeiten mit wir schlafen nicht ist das Sprecharrangement von wilde jagd im Vergleich zum früheren Text also genau das umgekehrte: Während in wir schlafen nicht sämtliche Aussagen der Interviewten von der unsichtbaren Erzählinstanz überschrieben werden - die scheinbar Schweigende also de facto ständig spricht -, kommt in wilde jagd paradoxerweise die permanent sprechende Erzählinstanz selbst gar nicht zu Wort. Die agency der Interview- und Erzählinstanz erweist sich in wir schlafen nicht über ihre Fähigkeit, sich fremde Diskurse anzueignen; in wilde jagd hingegen wird die agency der Sprecherin ,Kampusch“ von den sie überwuchernden Fremddiskursen geradezu erstickt beziehungsweise manifestiert sich nur noch in der schweigenden Verweigerung gegenüber dem medialen Geplapper. Die unausgesetzte Performanz der Sprecherin ,Kampusch“ erweist sich somit als inhaltlich leer. Just diese Leere wird dann von den diversen periphären Subjekten mit ihren je eigenen Diskursen ausgefüllt. Damit aber wird die reale Gewalt, welche ,Kampusch“ im Rahmen der Entführung angetan wurde, noch einmal auf symbolischer Ebene wiederholt. Irmtraud Hnilica schreibt hierzu: „Kampusch, die - als Entführte - literal absent gewesen ist, wird im Rahmen ihrer medialen und diskursiven Omnipräsenz erneut zum Verschwinden und Verstummen gebracht."1020 In wilde jagd ist ,Kampusch“ gezwungen, den Diskurs der Anderen aufzuführen. Die offenkundige Paradoxie dieser Konstellation besteht darin, dass der Diskurs der Anderen sich überhaupt nur über die zum Schweigen gebrachte Zentralinstanz ,Kampusch`legitimiert. Als parasitäre Subjekte sind die Figuren von wilde jagd auf ihren Wirt ,Kampusch` angewiesen; doch hindert sie das nicht daran, ,Kampusch` zumindest diskursiv vollständig aufzuzehren. ${ }^{1021}$

Während zu Beginn von wilde jagd alle Figuren dem Entführungsopfer ihre Unterstützung zusichern, werden im Fortgang des Textes die je eigenen, egoisti-

1020 Hnilica: „im berühmten eigenen ton“, S. 49.

1021 Zur Bedeutung des Parasitären in Rögglas Werk siehe Verena Meis: „Und ich denke mich auch brav in den Parasiten hinein“. Parasitäre Bewegungen bei Kathrin Röggla. In: Textpraxis 15/1 (2018). Quelle: http://www.unimuenster.de/textpraxis/verena-meis-parasitaere-bewe gungen-bei-kathrin-roeggla (Zugriff: 27.07.2021). Auch Hnilica schreibt von einem „blutsaugerischen Diskurs um Natascha Kampusch“ (Hnilica: „im berühmten eigenen ton“, S. 53). 
schen Motive immer deutlicher erkennbar. So lässt die „pseudo-psychologin“ ,Kampusch' wissen:

sie sei für mich da, sie stehe sozusagen auf meiner imaginären mitarbeiterliste. ich könne das als dienstleistung verstehen, was sie mache, das sei ja ein service für mich. natürlich habe sie auch ein eigenes interesse, wer wolle sein interesse in so einer situation auch leugnen, aber ich säße doch diesbezüglich am steuerpult [...] und das sei auch schon das, was sie mir mit auf den weg haben geben wollen, dass ich die sei, die die entscheidungen träfe, so grundsätzlich.

(ab, 137)

Tatsächlich aber wird die vorgebliche Entscheidungsfreiheit, die ,Kampusch“ anfangs noch eingeräumt wird, im Verlauf des Textes immer deutlicher beschnitten. Je weiter wilde jagd voranschreitet, umso deutlicher entpuppt sich das vermeintliche Interesse am eigentlichen Opfer der Entführung als ein nur dünn bemänteltes Interesse an der persönlichen oder medialen Verwertbarkeit des Falles. Anna Rutka bemerkt hierzu: „Die Spekulationen, Urteile und Kommentare des Publikums benutzen die Krise der Anderen als Projektionsfläche für eignes laszives Interesse, missbrauchen sie als Unterhaltungsstoff, um zum Schluss abzustumpfen und in [...] Gefühllosigkeit zu verfallen. “1022 Sukzessive wird ,Kampusch“ das Recht auf Privatsphäre abgesprochen: „so etwas habe ja einen symbolischen wert, wenn eine mal zurückkomme, wenn eine sich ins leben zurückmelde, und genau das hätte ich gemacht, auch wenn ich jetzt so tun würde, als ginge das niemanden etwas an.“ (ab, 131) Auch ,Kampuschs“ Fähigkeit zur Bewertung des eigenen Falles wird in Zweifel gezogen: ,alle wüssten jetzt, ich hätte überlebt, nur ich wisse es anscheinend noch nicht so ganz. jemand werde es mir sagen müssen, ein für alle mal sagen müssen." (ab, 132) ,Kampusch“ gerät damit „zur Nebenfigur ihres eigenen Dramas.“ ${ }^{1023}$ Selbst ihr Schweigen wird nicht als Folge eines Traumas oder als Reaktion auf die Bedrängung durch die Medien, sondern lediglich als Anzeichen mangelnder medialer Professionalität gedeutet: „also das finde er langsam etwas unprofessionell, dass ich nichts sagte.“ (ab, 158)

Der Mediendiskurs überschreibt somit das persönliche Erleben des Opfers und selbst noch die Fakten des Tathergangs, um an deren Stelle eine vermarktungsfähige Version des Falles zu setzen. Eine solchermaßen zugerichtete Version kommt den Projektionen und Erwartungen der Mediennutzer gerade zupass, insofern hier weniger die Fakten des Falles als dessen Emotionalisierungspotenziale zentral gesetzt werden:

1022 Rutka: Zeitgenössische Gesellschaft und ihre Ängste, S. 109.

1023 Hnilica: „im berühmten eigenen ton“, S. 49. 
der möchtegern-journalist: genau, hier gehe es doch nicht um details, hier gehe es um emotionen, die die leute mitgeliefert bekommen wollten und von denen sie bereits eine genaue vorstellung hätten. nicht, dass er das jetzt richtig finde, dass ich die frei haus lieferte, ich sollte ruhig geizen damit, aber auch dieser geiz müsse eine grenze haben.

$(\mathrm{ab}, 146)$

Die Auskunftsbereitschaft „Kampuschs‘ wird somit nicht in ihr eigenes Ermessen gestellt, sondern von außen aktiv eingefordert, und zwar in Abhängigkeit von der aufmerksamkeitsökonomischen Medienverwertbarkeit des Entführungsopfers und seiner Erlebnisse. Einen zentralen Aspekt dieser Verwertungsökonomie bildet dabei die Erwartung, dass ,Kampusch“, sobald der Höchstwert der medialen Erregungskurve überschritten ist, auch wieder aus dem öffentlichen Diskurs heraustreten werde: „der möchtegern-journalist: er müsse sagen, rein taktisch wäre es besser für mich, es wäre mal langsam schluss mit mir. denn die leute seien genervt und wollten nichts mehr von mir hören.“ (ab, 165) Die Formulierung, es solle ,mal langsam schluss mit ihr' sein, lässt dabei deutlich die Aggression erkennen, die ,Kampusch` infolge des Überdrusses an der ihren Fall betreffenden medialen Berichterstattung entgegenschlägt: Der vorgängige Solidaritätsdiskurs wandelt sich zusehends zur „hate speech““ ${ }^{1024}$ Gerade ihr außergewöhnliches und leidvolles Schicksal wird ,Kampusch“ letztlich zum Vorwurf gemacht, da es innerhalb der Koordinaten der Aufmerksamkeitsökonomie nicht anders denn als strategischer Positionierungsvorteil erscheinen kann. Nach dem Abflachen der medialen Aufmerksamkeitskurve wird dem Opfer das Recht abgesprochen, das eigene „weiterleben“ öffentlich zu thematisieren. ${ }^{1025}$ So merkt die „pseudo-psychologin“ an: „auch in ihren augen machte ich mich verdächtig, wenn ich allzu euphorisch von meinem weiterleben spräche.“ (ab, 152) ,Kampusch“ wird somit gewissermaßen ein drittes Mal zum Verschwinden gebracht: Nach der realen Entführung und der Überschreibung ihres Schicksals durch die sensationslüsternen Medien wird

1024 Monika Szczepaniak: Elfriede Jelinek und Kathrin Röggla „in Mediengewittern“. In: Joanna Drynda / Marta Wimmer (Hg.): Neue Stimmen aus Österreich. 11 Einblicke in die Literatur der Jahrtausendwende. Frankfurt a. M. 2013, S. 25-35, hier S. 33. Im Anschluss an Judith Butler liest auch Bartl „Sprechakte als Gewaltakte, die auf NK [i. e. ,Kampusch'] eine wohl ähnlich verheerende Wirkung haben wie das erlittene Verbrechen.“ (Bartl: „Natascha“, S. 231).

1025 Der Vorwurf, Kampusch habe mit ihrer Geschichte öffentliche Aufmerksamkeit erschleichen wollen, wird auch in Elfriede Jelineks Stück Winterreise aufgegriffen: „Sie ist jetzt doch wieder draußen, was will sie noch? Will sie sich über uns stellen? Will sie ewig ein Angedenken sein für uns? Woran? Wozu? Was will sie? Unsere Schmerzen schweigen doch auch, jedenfalls meistens. Warum schweigt dann sie nicht? Unsere Schmerzen sind wichtiger. Sie könnte viel besser schweigen als sprechen. Sie ist ein Opfer. Wir wollen hier keine Opfer. Wir haben schon genug Opfer. Sie soll wieder weg.“ (Elfriede Jelinek: Winterreise. Reinbek bei Hamburg 2011, S. 34f.). 
sie, sobald ihr Fall hinreichend ausgeschlachtet ist, wiederum aus dem öffentlichen Diskurs ausgeschlossen. ${ }^{1026}$ Das Opfer der Entführung gerät damit nach seiner Befreiung nicht nur zum Opfer der titelgebenden ,wilden Jagd‘, der Verfolgung also durch Medien und Einzelpersonen ${ }^{1027}$; die finale Kränkung besteht darin, dass sich diese Medien und Einzelpersonen, nachdem das Opfer ihrer Jagd aufmerksamkeitsökonomisch ,erlegt‘ ist, für die Einzelperson ,Kampusch“ gar nicht mehr interessieren.

Röggla bringt in wilde jagd die medialen und persönlichen Diskurse zur Aufführung, die sich um einen Fall wie denjenigen Natascha Kampuschs herumgruppieren. Dabei kritisiert der Text die Subjektpositionen, welche das Mediendispositiv der Gegenwart für parasitäre Akteure eröffnet. Das vorgeschützte Mitleid der Sprecher wird in wilde jagd letztlich als bloßer Vorwand enttarnt, um Zugriff auf das Opfer der Entführung zu erhalten und damit an dem Medienhype rund um dessen Befreiung partizipieren zu können. Sowohl die Perspektive ,Kampuschs` als auch die Fakten rund um den Tathergang werden dabei von einem medialen Diskurs überdeckt, für den Erwägungen des Respekts, der Solidarität oder der Wahrheitsliebe schlussendlich keine Rolle spielen, sondern der allein auf die Generierung maximaler öffentlicher Aufmerksamkeit, eine Emotionalisierung der Berichterstattung sowie die Einpassung des Falles in eine bestimmte, vorgefertigte Mediendramaturgie abzielt.

Der kreative Dokumentarismus von wilde jagd - falls man hier überhaupt noch von Dokumentarismus sprechen kann - versucht nicht, seine Leser über einen bestimmten Tathergang zu informieren oder einzelne Fakten zu archivieren (für diejenigen Leser, die mit dem Fall Kampusch nicht vertraut sind, dürfte wilde jagd weitgehend unverständlich sein). Röggla praktiziert hier vielmehr einen dekonstruktiven Meta-Dokumentarismus, der andere Dokumentarismen kritisiert, jene Pseudo-Dokumentarismen der realen Welt nämlich, welche mehr an der medialen und persönlichen Verwertbarkeit eines bestimmten Stoffes als an diesem Stoff selbst interessiert sind und die einen

$1026 \mathrm{Zu}$ beachten ist hier der Publikationszeitpunkt von die alarmbereiten im Jahr 2010, also nur vier Jahre nach dem medialen Aufruhr um Kampuschs Selbstbefreiung. Nachdem Kampusch seither mit mehreren Interviews, einer eigene Talk-Show-Sendung und zwei Autobiografien aktiv in die mediale Öffentlichkeit getreten ist, wird man die These vom schweigenden Opfer wohl kaum noch aufrechterhalten können. Für den Text wilde jagd ist dieser Umstand allerdings weitgehend bedeutungslos: Rögglas kreativer Dokumentarismus bezieht sich insgesamt nicht so sehr auf den konkreten Fall Kampusch als auf jene Diskurse, die sich um diesen Fall oder auch um ähnliche Fälle herumgruppieren.

1027 Siehe zur Ausgestaltung der „Jagdmotivik“ in wilde jagd Bartl: „Natascha“, S. 231, Anm. 33. 
Fall wie denjenigen Kampuschs lediglich zum Anlass nehmen, um die eigenen, letztlich immer schon vorgefertigten Erwartungen, Projektionen und Diskurse aufzurufen und abzuspulen. ${ }^{1028}$

Wie lässt sich nun aber das dokumentarische Verfahren von wilde jagd ins Verhältnis zur Kontrafaktik setzen? Anders als in wir schlafen nicht muss die Authentizität des Faktenmaterials in wilde jagd nicht erst paratextuell beglaubigt werden: Eine Vertrautheit mit dem Fall Kampusch kann bei der Leserschaft vorausgesetzt werden. Doch variiert Röggla in wilde jagd nicht die konkreten Details des Falles, sodass auch in diesem Text keine konkreten kontrafaktischen Elemente identifizierbar sind. Als Faktenmaterial dienen nicht einzelne Informationen des Falles Kampusch, sondern jene Diskurse, die sich um diesen Fall herum ansiedeln. Eine Variation des Faktenmaterials liegt dabei in wilde jagd wiederum primär in formaler Hinsicht vor: Erzeugt wird eine offenkundig künstliche Sprechsituation, in der ,Kampusch` dazu gezwungen wird, die Diskurse ihrer parasitären Peiniger aufzuführen. Auch dürfte die unmetaphorische ,wilde Jagd' des Textes - ,Kampusch“ wird in der fiktionalen Welt von ihren Peinigern ganz real durch die Stadt gehetzt - in der Realität so nicht stattgefunden haben. Ferner weist der Text die bekannten rögglaschen Verfremdungseffekte auf - Konjunktiv, ironische Überspitzung, kritisch-strategisches Textarrangement, Einsatz unheimlicher Bilder ${ }^{1029}$ - und deutet so auf die zumindest partielle Eigenständigkeit der fiktionalen Welt hin. Die wohl wichtigste Faktenvariation gegenüber den realen medialen Diskursen rund um den Fall Kampusch besteht allerdings darin, dass in Rögglas Text der eigentliche ,Faktenkern' fast gänzlich ausgespart bleibt: Anders als in der realen medialen Berichterstattung erfährt man aus Rögglas Text so gut wie nichts über Kampuschs Entführung und Befreiung oder über das Erleben der involvierten Personen.

Diese Verfremdung des dokumentierten Diskurses respektive die kontrafaktische Variation des Faktenmaterials erweist sich bei wild jagd - ähnlich wie bereits bei wir schlafen nicht - als eine Strategie der künstlerischen Kritik. Indem Röggla in ihrem satirisch-kontrafaktischen Text den Diskurs ,Kampuschs“ vollständig hinter den Peridiskursen der opportunistischen Rahmensubjekte verschwinden lässt, macht sie darauf aufmerksam, dass auch in der realen Welt

1028 In ähnlicher Weise hält Moser für den ersten Text die zuseher innerhalb des Bandes die alarmbereiten fest: „Er [i. e. der Text] zitiert und imitiert den Dokumentarismus und kritisiert ihn zugleich, indem er die Rolle der Fiktion und insbesondere des Genres für dokumentarisches Erzählen offenlegt.“ (Moser: Echtzeit-Fiktion, S. 168).

1029 So wird etwa der Assoziationsbereich des Gespenstischen in wilde jagd wieder aufgerufen, wenn „das verschenkte nachwuchstalent“ sich beschwert: ,ich reagierte nicht wirklich auf ihn. ich sähe ihn nur an, als wäre er ein gespenst. dabei sei ich hier das gespenst, wenn schon einer hier das gespenst sein müsse.“ (ab, 154, 156). 
die eigentliche Faktenbasis, inklusive der subjektiven Opferperspektive, von den Eigendynamiken der medialen Erregungsdramaturgie in den Hintergrund gedrängt zu werden droht (hierin weist wilde jagd durchaus über den Einzelfall Kampusch hinaus). Indem Rögglas Text ,Kampusch“ zum Schweigen bringt respektive sie nur fremde Worte artikulieren lässt, stellt er die Pseudo-Authentizität eines medialen Voyeurismus heraus, der die Sache selbst zu präsentieren vorgibt, dabei aber tatsächlich nur eine eigene, medienstrategisch günstige Positionierung anstrebt und vorgefasste Erwartungen bestätigt sehen will.

Insgesamt setzt Röggla in wilde jagd - wie überhaupt in den Texten von die alarmbereiten - den etablierten medialen Formanten kein alternatives dokumentarisches Format entgegen, das zur Präsentation des relevanten Faktenmaterials besser geeignet wäre. Stattdessen macht Röggla mit ihrem kreativen Dokumentarismus darauf aufmerksam, dass der bloße Anspruch, anhand dokumentarischer Verfahren zu einem ,eigentlichen` Wahrheitskern vorzudringen, problematisch ist; und dass darüber hinaus populäre dokumentarische Formate oftmals gar nicht sonderlich an den von ihnen verhandelten Fakten - wenn es solche denn überhaupt noch gibt - interessiert sind. Ähnlich wie in wir schlafen nicht treten also auch in die alarmbereiten die künstlerische Verfremdung und kontrafaktische Variation des Faktenmaterials in ein Resonanzverhältnis zu den Faktenmanipulationen der realen Medienlandschaft.

Im Rahmen von Rögglas kreativem Dokumentarismus eröffnet die Kontrafaktik - anders als in ihren klassischen Ausprägungen, etwa im alternativgeschichtlichen Roman - keine Alternativen zur realen Welt; Kontrafaktik bildet vielmehr ein künstlerisches Parallelphänomen und Analogverfahren zu den strategischen Faktenproduktionen der Realität. Als konstitutiv faktenvariierendes Erzählverfahren kommt der Kontrafaktik im Werk Rögglas die Funktion zu, auf die realen Destabilisierungen der Gegenwart hinzuweisen. Dass angesichts von Rögglas postmoderner Epistemologie und der Hybrid-Ästhetik ihres Werks die Kontrafaktik als Verfahren und Referenzstruktur mitunter nicht mehr eindeutig bestimmbar ist, stellt dabei keinen grundsätzlichen Einwand gegen eine Applikation dieser Kategorie auf Rögglas Texte dar. Im Gegenteil: Gerade das ,Stottern der Kontrafaktik` macht - in Analogie zum „stottern des realismus“1030 im Werk Kathrin Rögglas die Logik realweltlicher Faktenproduktion ästhetisch erfahrbar und ermöglicht somit eine genuin künstlerische Dokumentation der prekären Wahrheitsproduktion der Gegenwart.

1030 Röggla: das stottern des realismus. 